Article

\title{
The E. coli Global Regulator DksA Reduces Transcription during T4 Infection
}

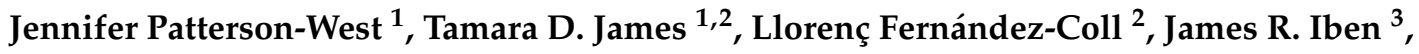 \\ Kyung Moon ${ }^{1}$, Leslie Knipling ${ }^{1}$, Michael Cashel ${ }^{2}$ and Deborah M. Hinton ${ }^{1, *}$ \\ 1 Gene Expression and Regulation Section, Laboratory of Cell and Molecular Biology, \\ National Institute of Diabetes and Digestive and Kidney Diseases, National Institutes of Health, Bethesda, \\ MD 20814, USA; jennifer.west@nih.gov (J.P.-W.); tamara.james@ihs.gov (T.D.J.); \\ kyung.moon@nih.gov (K.M.); lesliek@mail.nih.gov (L.K.) \\ 2 Section on Microbial Regulation, Eunice Kennedy Shriver National Institute of Child Health and Human \\ Development, National Institutes of Health, Bethesda, MD 20814, USA; \\ llorenc.fernandezcoll@nih.gov (L.F.-C.); cashelm@mail.nih.gov (M.C.) \\ 3 Molecular Genomics Core, Eunice Kennedy Shriver National Institute of Child Health and Human \\ Development, National Institutes of Health, Bethesda, MD 20814, USA; james.iben@nih.gov \\ * Correspondence: dhinton@helix.nih.gov; Tel.: +1-301-496-9885
}

Received: 28 March 2018; Accepted: 24 May 2018; Published: 6 June 2018

\begin{abstract}
Bacteriophage T4 relies on host RNA polymerase to transcribe three promoter classes: early ( $\mathrm{Pe}$, requires no viral factors), middle ( $\mathrm{Pm}$, requires early proteins MotA and $\mathrm{Asi}$ ), and late ( $\mathrm{Pl}$, requires middle proteins gp55, gp33, and gp45). Using primer extension, RNA-seq, RT-qPCR, single bursts, and a semi-automated method to document plaque size, we investigated how deletion of DksA or ppGpp, two E. coli global transcription regulators, affects T4 infection. Both ppGpp ${ }^{0}$ and $\triangle d k s A$ increase T4 wild type (wt) plaque size. However, ppGpp ${ }^{0}$ does not significantly alter burst size or latent period, and only modestly affects T4 transcript abundance, while $\Delta d k s A$ increases burst size (2-fold) without affecting latent period and increases the levels of several Pe transcripts at 5 min post-infection. In a T4mot $A^{a m}$ infection, $\Delta d k s A$ increases plaque size and shortens latent period, and the levels of specific middle RNAs increase due to more transcription from Pe's that extend into these middle genes. We conclude that DksA lowers T4 early gene expression. Consequently, $\Delta d k s A$ results in a more productive wt infection and ameliorates the poor expression of middle genes in a T4mot $A^{a m}$ infection. As DksA does not inhibit Pe transcription in vitro, regulation may be indirect or perhaps requires additional factors.
\end{abstract}

Keywords: bacteriophage T4; DksA; MotA; RNA-seq; transcriptome analysis

\section{Introduction}

The integrity and regulation of gene expression is essential for proper cellular function and adaptation. Bacteria have evolved myriad mechanisms to tightly regulate gene expression to ensure that genes are expressed under the correct environmental conditions [1]. Bacteriophages have simultaneously evolved mechanisms for altering gene expression in their host to optimize the expression of genes required for viral proliferation [2-4].

Bacterial transcription is performed by an RNA polymerase (RNAP), which consists of five core factors ( $\alpha \mathrm{I}, \alpha \mathrm{II}, \beta, \beta^{\prime}$, and $\omega$ ), along with a $\sigma$ subunit that specifies the transcription start site (reviewed in $[5,6])$. In Escherichia coli (E. coli), the primary $\sigma$ factor, $\sigma^{70}$, recognizes specific -10 and -35 elements within the promoter sequence and is essential for the transcription of genes needed for exponential growth under nutrient-rich conditions. Efficient transcription requires the interaction of RNAP with promoter DNA to create an "open complex" with a single-stranded region at the transcription start 
site, initiation of RNA synthesis, promoter clearance, processive transcription elongation, and accurate termination (reviewed in [7]).

E. coli promoters use specific activators, repressors, and/or other transcriptional regulators to control initiation, elongation, and termination. While activators and repressors typically interact with specific DNA sequence motifs, DksA is a member of a growing class of global transcription regulators, called secondary $\left(2^{\circ}\right)$ channel proteins, that interact with just RNAP. These proteins, which also include GreA and GreB, all share two superimposable structural domains: a coiled-coil domain that penetrates the $2^{\circ}$ channel of RNAP and a globular domain that binds the rim helices of RNAP atop the $2^{\circ}$ channel [8]. The acidic residues at the tip of the coiled-coil have protein-specified, DNA context-determined effects on catalysis during transcription initiation as well as elongation and fidelity [9]. These features culminate in activation/inhibition of RNA synthesis (diester formation) as well as diesterase cleavage of backtracked mRNA to rescue transcription arrest [10].

The interaction of DksA with RNAP generates one of two binding sites for the small molecule ppGpp on polymerase [11,12], and in most cases, DksA activity is dependent on ppGpp. While the level of DksA is relatively constant in exponentially growing cells, the concentration of ppGpp increases dramatically under nutrient-poor conditions or other stresses [13,14]. The physiological roles of DksA and ppGpp in E. coli gene expression are complicated. DksA/ppGpp inhibition of RNAP initiation from the ribosomal promoter PrrnB1 is the most widely studied example, where DksA and ppGpp act synergistically to further destabilize already unstable open complexes [12,14-16]. In contrast, ppGpp without the help of DksA can inhibit the strong phage lambda pR promoter that forms stable open complexes, not by destabilizing the open complex but rather by inhibiting promoter escape [17]. In other instances, identical, independent, or even opposing regulatory roles have been reported for the two regulators in E. coli cells [18]. In addition, ppGpp can bind a variety of proteins with regulatory effects independent of transcription [19]. Furthermore, DksA has a cysteine zinc-finger motif that acts independently of ppGpp to sense oxidative stress [20]. It is noteworthy that GreA and GreB are competitive with DksA in binding to RNAP in order to rescue backtracked, arrested, or paused RNAP, primarily during transcription elongation [21,22].

In a bacteriophage $\mathrm{T} 4$ infection, there are three types of $\mathrm{T} 4$ promoters (early $(\mathrm{Pe})$, middle $(\mathrm{Pm})$, and late (Pl)) based on the stage of development in which they are active (reviewed in [23]). Pe's, which contain a strong match for the $\sigma^{70}$-dependent consensus -10 and -35 elements, do not require any viral factors for activity and are active immediately after infection. Thus, Pe's successfully compete with host DNA for the same pool of RNAP. Pm's, which become active $\sim 1 \mathrm{~min}$ after infection at $37^{\circ} \mathrm{C}$, require two T4-encoded proteins, MotA and AsiA, to direct RNAP to recognize a specific element, a MotA Box, centered at -30. Importantly, middle genes are also expressed through the extension of early transcription from Pe's into downstream middle genes. Finally, $\mathrm{Pl}^{\prime} \mathrm{s}$ become active $\sim 5-7 \mathrm{~min}$ after infection at $37^{\circ} \mathrm{C}$. Pl's harbor a novel -10 sequence known as the late TATA box and require the T4 proteins gp55 (late sigma factor) and gp33 (co-activator) for activity. In addition, late transcription requires active T4 DNA replication through T4 protein gp45, which is the replication sliding clamp that also serves as an enhancer for Pl's [24]. As a further complication, phage T4 DNA is modified by glucosylated, hydroxymethyl 5-cytosine, a moiety that can alter RNAP activity as well as the interactions of factors that normally function with unmodified DNA templates.

In this study, we report the first global transcriptome analyses of T4 wild type (wt) and a T4 mot $A$ knockdown (T4mot $A^{a m}$ ) infections of a wild-type laboratory strain and a $d k s A$ mutant host strain, and we investigate the effects of a DksA or ppGpp deletion on T4 growth and transcription. We demonstrate that a deletion of either DksA or ppGpp results in significantly larger plaques for either T4 wt or T4mot $A^{a m}$. Infections in a ppGpp ${ }^{0}$ host have a marginal effect on burst size, latent period, or phage transcript abundance. However, a deletion of DksA results in a 2-fold increase in T4 wt burst size and increased levels of several Pe RNAs. As the T4 activator MotA is required for Pm activation, a T4 mot $A$ knockdown results in poor phage growth. Our transcriptome analyses reveal that middle genes are affected differentially, ranging from slight to severe inhibition of gene expression. 
We show that the absence of DksA in the T4 mot $A$ knockdown background also increases transcription from specific Pe's. This increase ameliorates the poor growth of T4mot $A^{a m}$ by increasing expression of downstream middle genes needed for replication, recombination, and late transcription. As we do not observe an effect of DksA on Pe transcription in a purified in vitro transcription system, we speculate that DksA decreases T4 early transcription through other changes present in the infected $\Delta d k_{s} A$ host or by using additional host/phage factors.

\section{Materials and Methods}

\subsection{Phage and Strains}

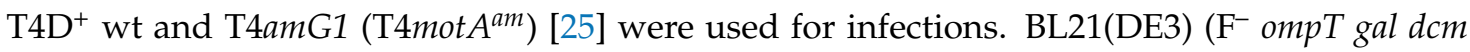
lon hsd $S_{B}\left(r_{B}{ }^{-} m_{B}{ }^{-}\right) \lambda\left(\text { DE3 (lacI lacUV5-T7p07 ind1 sam7 nin5)) (malB }{ }^{+}\right)_{\mathrm{K}-12}\left(\lambda^{\mathrm{S}}\right)$ ) [26] and B606 (alias REL606), an ancestral B strain of R. Lenski $\left(\mathrm{str}^{\mathrm{r}}, \mathrm{r}^{-} \mathrm{m}^{-}, \mathrm{T} 6^{\mathrm{r}}\right.$, ara ${ }^{-}$) [27] were the parental strains used in this study. Here, strains that bear the functional alleles at the $d k s A$, relA, and spoT loci are referred to as wild type. B606 $\Delta d k s A:: k a n$ (B606 $\Delta d k s A$ ) was constructed by P1 transduction using a K-12 lysate containing the $\Delta d k s A:: k a n$ insertion [28]. B606 ppGpp ${ }^{0}$, an isogenic mutant strain that is unable to generate ppGpp, was constructed by introducing a $\Delta$ relA::kan insertion followed by a $\Delta$ spoT::cat insertion as previously described [29]. Briefly, the $\mathrm{d} k s A$, relA and spoT mutants were constructed by P1 transduction with $E$. coli $\mathrm{K}-12$ donor strains and the recipient $\mathrm{B} 606$ strain. The $\Delta d k s A:: k a n$ insertion recombinant in B606 grows on LB but not on M9 glucose minimal, like the MG1655 K-12 sister strain. Transduction of the $\Delta$ relA::kan recombinant allele into B606 was phenotypically verified by loss of resistance to 3-aminotriazole as well as the absence of ppGpp accumulation after adding $1 \mathrm{mg} / \mathrm{mL}$ serine hydroxamate. The B606 $\Delta$ relA::kan $\Delta$ spoT::cat double deletion construct was made by introducing the $\triangle$ relA mutant first, then transduction of the $\triangle$ spoT mutant since the $\triangle$ spoT rel $A^{+}$combination is not viable owing to excessive ppGpp levels. Features of the double mutant again mimic those of the K-12 sister strain and are unable to grow on minimal medium without amino acid supplementation.

\subsection{Quantification of Plaque Size}

BL21(DE3), B606, B606 $\Delta d k s A$, and B606 ppGpp ${ }^{0}$ were freshly streaked out on Lennox L Broth (LB; Quality Biological (Gaithersburg, MD, USA): $5 \mathrm{~g} / \mathrm{L}$ sodium chloride, $10 \mathrm{~g} / \mathrm{L}$ tryptone, and $5 \mathrm{~g} / \mathrm{L}$ yeast extract) plates and grown at $37^{\circ} \mathrm{C}$ overnight. For B606 $\Delta d k s A$, a final concentration of $3 \mu \mathrm{g} / \mathrm{mL}$ adenine was added to plates to improve growth for single colony selection. From a single colony, cultures were grown overnight in LB at $32{ }^{\circ} \mathrm{C}$. For plating, cultures were diluted in fresh LB to an $\mathrm{OD}_{600} \sim 0.1$ and grown to early-log phase $\left(\mathrm{OD}_{600} \sim 0.3\right)$ at $32^{\circ} \mathrm{C}$. Cells were then transferred to ice until ready to titer. For each titer, $\sim 50$ to 100 phages in $200 \mu \mathrm{L} \mathrm{LB}$ were incubated with an equal volume of culture for $5 \mathrm{~min}$, followed by $3 \mathrm{~mL}$ of $0.65 \%(w / v)$ Drake Top agar at $48{ }^{\circ} \mathrm{C}$ [30], and then plated on $1.5 \%(w / v)$ LB agar. Plates were incubated at $37^{\circ} \mathrm{C}$ overnight.

Digital images of each plate were documented using a Protein Simple Molecular Imager Gel Doc (San Jose, CA, USA). TIFF image files were converted to JPEG files with 256 gray levels (0-255) and $650 \times 515$ pixels resolution in ImageJ [31]. Plaque size was then measured by particle analysis in pixels squared [32]. Individual plaque area measurements were uploaded into R studio [33] and density plots for each replicate were generated using ggplot2 [34]. Density plots provided a visual representation of the distribution of plaque area measurements for each sample.

\subsection{Burst Size Analysis}

Burst size experiments were performed as previously described [35] for single-step growth experiments with the following modifications. B606, B606 $\Delta d k s A$, and B606 ppGpp ${ }^{0}$ were grown overnight at $32{ }^{\circ} \mathrm{C}$ from a single colony, diluted to an $\mathrm{OD}_{600} \sim 0.1 \mathrm{in} \mathrm{LB}$, and then cultured to mid-log phase $\left(\mathrm{OD}_{600} \sim 0.5\right)$ at $37^{\circ} \mathrm{C}$. For all conditions, B606 wt was kept on ice and used as the plating strain. For each condition, $900 \mu \mathrm{L}$ of culture was transferred to a $1.5 \mathrm{~mL}$ microcentrifuge tube (pre-warmed to 
$37^{\circ} \mathrm{C}$ ) containing either T4 wt or T4mot $A^{a m}$ at a multiplicity of infection (MOI) of $<0.04$. After $10 \mathrm{~min}$, the phage infected sample was diluted 10,000-fold for T4 wt or 1000-fold for T4mot $A^{\text {am }}$. Dilutions were gently vortexed to mix and immediately returned to $37^{\circ} \mathrm{C}$. For pre-burst $(\leq 30 \mathrm{~min})$ and post-burst (35 to $80 \mathrm{~min}$ ) time points, $100 \mu \mathrm{L}$ or $10 \mu \mathrm{L}$ of the diluted phage culture, respectively, was added to $100 \mu \mathrm{L}$ of $\mathrm{B} 606 \mathrm{wt}$. This was immediately followed by the addition of $3 \mathrm{~mL}$ of $0.65 \%(w / v)$ Drake Top agar $\left(\right.$ at $50{ }^{\circ} \mathrm{C}$ ) and plating on $1.5 \%(w / v)$ LB agar. Plates were incubated overnight at $37^{\circ} \mathrm{C}$. Burst size was calculated by dividing the average number of plaques for the post-burst time points (50 to $70 \mathrm{~min}$ for $\mathrm{T} 4 \mathrm{wt}$ infection) by the average number of plaques for pre-burst time points ( 15 to $30 \mathrm{~min}$ for $\mathrm{T} 4 \mathrm{wt}$ infections). The latent period is defined as the last time point post-infection for which the relative titer remains less than or equal to 2 .

\subsection{Purification of RNA}

B606, B606 $\Delta d k s A$, and B606 ppGpp ${ }^{0}$ were grown at $37^{\circ} \mathrm{C}$ to early $/ \mathrm{mid} \log$ phase (OD600 0.4), then infected at an MOI of 10 with either T4 wt or T4mot $A^{a m}$. RNA was isolated at 1, 5, or $12 \mathrm{~min}$ post-infection using method II [36]. Briefly, T4 infections were rapidly stopped by mixing samples with a frozen solution containing $100 \mu \mathrm{g} / \mathrm{mL}$ chloramphenicol, cells were lysed by treatment with hot phenol, nucleic acid was precipitated with ethanol, the isolated nucleic acid was treated with DNase, and RNA was isolated by phenol extraction followed by ethanol precipitation.

Total RNA used for RNA-seq was assessed on a Bioanalyzer using the Agilent RNA 6000 Nano Kit (Santa Clara, CA, USA) to evaluate the quality of samples; all samples used for library preparation had an RNA integrity number (RIN) of 9.3 or better [37]. The quality of total RNA used for real-time quantitative polymerase chain reaction (RT-qPCR) and primer extensions was evaluated using a $0.8 \%$ $(w / v)$ agarose gel stained with ethidium bromide.

\subsection{RNA-seq}

Total RNA $(2.5 \mu \mathrm{g})$ from each sample was treated with a Ribo-Zero rRNA Removal Kit (Gram-Negative Bacteria; Illumina, San Diego, CA, USA) to deplete ribosomal RNAs. A TruSeq Stranded mRNA Library Prep Kit (Illumina, San Diego, CA, USA) was then used for the cDNA library preparation, and the library was sequenced using Illumina MiSeq in order to obtain 100 bp paired end reads.

After trimming, FASTQ files were aligned to E. coli B str. DE3 (NC_012971.2) as a reference genome using STAR v2.5.2 retaining unmapped reads [38]. Unmapped reads, presumably stemming from the T4 phage genome, were then mapped to the T4 reference genome (NC_000866.4). In both cases, default alignment behavior was altered with the following arguments: --outFilterScoreMinOverLread 0 --outFilterMatchNmin 30 --outFilterMatchNminOverLread 0 --clip3pAdapterSeq AGATCGGAAGAG CGTCGTGTA --alignIntronMax 1. RNA gene counts in both reference genomes were then quantified using the same NCBI gene definitions utilized in mapping index construction using the subread featureCounts v1.4.6-p3 package [39]. Differential expression between samples and control was represented as a fold change, and genes with both a fold change $\geq 2$ and $p$ value $\leq 0.05$ were considered significant. RNA-seq data is available in the National Center for Biotechnology Information (NCBI) database (GEO number GSE111808) and in Table S1.

\subsection{Primer Extension Analyses}

Primer extension was performed using Avian Myeoloblastosis Virus (AMV) reverse transcriptase (Life Sciences, Inc., St. Petersburg, FL, USA) as previously described [40-42], using the RNA sample ( $2 \mu \mathrm{g}$ for the $1 \mathrm{~min}$ time points, $4 \mu \mathrm{g}$ for other time points) and $1 \mathrm{pmol}$ of $5^{\prime}{ }^{32} \mathrm{P}$-labeled primer. Unless otherwise indicated, oligonucleotides annealed 100 nucleotides (nt) downstream of the predicted start site of the promoter. Primer sequences are available upon request. Primer extension products were separated on $5 \%(w / v)$ denaturing polyacrylamide (19:1, acrylamide:bis) gels and visualized by autoradiography. Product levels were quantified using a GS-800 calibrated densitometer (Bio-Rad, Inc., Hercules, CA, USA) and Quantity One Software (Bio-Rad, Inc.) 


\section{7. $R T-q P C R$}

RT-qPCR was used to validate RNA-seq data. Briefly, RNA samples were collected under the same conditions used for RNA-seq, and complementary DNA (cDNA) was generated using a High Capacity cDNA Reverse Transcription Kit (Applied Biosystems, Foster City, CA, USA). Target genes were amplified with SYBR Green PCR Master Mix (Applied Biosystems) in a LightCycler 480 instrument (Roche Molecular Diagnostics, Pleasanton, CA, USA). Relative levels of gene expression were determined with the comparative $C_{T}$ method, also known as $2^{-\Delta \Delta C t}$ [43]. Genes $n r d A$ (B606 $\Delta d k s A$ vs. B606 wt) and 61.4 (T4mot $A^{a m}$ vs. T4 wt) that appeared unaffected in the RNA-seq data were used as internal controls. Primers used in this study were designed using Primer3web [44,45]; primer sequences are available upon request.

\subsection{Proteins}

Core RNAP was purchased from New England Biolabs, and $\sigma^{70}$ [46], MotA [47], and AsiA [48] were purified as previously described. DksA containing a C-terminal $\mathrm{His}_{6}$ tag was isolated and purified from CF9413:MG1655 ( $\lambda$ DE3)/pHM1501 [49] grown in $500 \mathrm{~mL}$ of LB (Quality Biological) containing $50 \mu \mathrm{g} / \mathrm{mL}$ carbenicillin at $37^{\circ} \mathrm{C}$ with shaking until mid-log phase. At an $\mathrm{OD}_{600}$ of $\sim 0.35$, protein synthesis was induced by the addition of $0.2 \mathrm{mM}$ IPTG (final concentration) for $2 \mathrm{~h}$ with shaking. Cells were harvested by centrifugation at $13,000 \times g$ for $10 \mathrm{~min}$. The following procedures were performed on ice or at $4{ }^{\circ} \mathrm{C}$. Pellets were resuspended in $12 \mathrm{~mL}$ of lysis buffer $(40 \mathrm{mM}$ Tris- $\mathrm{HCl}$ (pH 8.0), $300 \mathrm{mM} \mathrm{NaCl}, 5 \mathrm{mM}$ imidazole, $2 \mathrm{mM}$ 2-mercaptoethanol, $0.1 \mathrm{mM}$ benzamidine; 2- $5 \mathrm{~mL}$ per gram wet weight) and lysed by sonication. Clarified supernatant was obtained by centrifugation at $15,000 \times g$ for $30 \mathrm{~min}$ and added to $2 \mathrm{~mL}$ of a $50 \%$ slurry of equilibrated Ni-NTA agarose (QIAGEN, Hilden, Germany) in lysis buffer and rocked gently overnight. The lysate/Ni-NTA mixture was loaded onto a Bio-Rad $10 \mathrm{~mL}$ disposable column, washed twice with five bed volumes of wash buffer $(40 \mathrm{mM}$ Tris- $\mathrm{HCl}$ (pH 8.0), $300 \mathrm{mM} \mathrm{NaCl}, 10 \mathrm{mM}$ imidazole, $2 \mathrm{mM}$ 2-mercaptoethanol), and then with $4 \mathrm{~mL}$ each of wash buffer containing increasing imidazole concentrations: $60 \mathrm{mM}, 150 \mathrm{mM}$, and $250 \mathrm{mM}$. Although all imidazole fractions contained DksA, the $250 \mathrm{mM}$ fraction was highly purified (Figure S1). This fraction was pooled and dialyzed in DksA Storage Buffer $(25 \mathrm{mM}$ Tris- $\mathrm{HCl}(\mathrm{pH} 8.0), 100 \mathrm{mM}$ $\mathrm{NaCl}, 0.5 \mathrm{mM}$ ethylenediaminetetraacetic acid (EDTA), 50\% glycerol, $2 \mathrm{mM}$ 2-mercaptoethanol) and stored at $-20^{\circ} \mathrm{C}$.

\subsection{In Vitro Transcription}

In order to check the activity of purified DksA, in vitro transcription assays were performed using a supercoiled template DNA that contains the ribosomal promoter, PrrnBP1 ( $r r n B$ sequence -180 to +109 ) [49] as a positive control or a DNA template, PS17 (gift of J. Nguyen) that contains a $\sigma^{70}$-dependent promoter that is not affected by DksA as a negative control. Transcription reactions $(10 \mu \mathrm{L}$ ) were assembled with $5 \mathrm{nM}$ DNA, $30 \mathrm{nM}$ RNAP (final concentration; sigma:core ratio of 2.5:1) that had been reconstituted with or without $250 \mu \mathrm{M} \mathrm{ppGpp} \mathrm{(final} \mathrm{concentration),} \mathrm{the} \mathrm{indicated}$ concentration of DksA, and transcription buffer (50 mM Tris-acetate ( $\mathrm{pH} 8.0), 10 \mathrm{mM}$ magnesium acetate, $10 \mathrm{mM}$ 2-mercaptoethanol, $90 \mathrm{mM}$ potassium glutamate, $10 \mu \mathrm{g} / \mathrm{mL}$ bovine serum albumin). Solutions were incubated at $37^{\circ} \mathrm{C}$ for $10 \mathrm{~min}$ before single round transcription was initiated by the addition of heparin (final concentration of $100 \mu \mathrm{g} / \mathrm{mL}$ ) and ribonucleoside triphosphates (rNTPs; final concentration of $200 \mu \mathrm{M}$ each ATP, GTP, CTP and $20 \mu \mathrm{M}\left(\alpha_{-}{ }^{32} \mathrm{P}\right)$ UTP at $\left.1.7 \times 10^{4} \mathrm{dpm} / \mathrm{pmol}\right)$. After incubation for $10 \mathrm{~min}$ at $37^{\circ} \mathrm{C}$, reactions were collected on dry ice. A solution $(10 \mu \mathrm{L})$ containing $10 \mathrm{mM}$ EDTA (pH 7.0), 0.1\% bromophenol blue, and $0.1 \%$ xylene cyanol in deionized formamide was added. Samples were then heated for $2 \mathrm{~min}$ at $95^{\circ} \mathrm{C}$ and $10 \mu \mathrm{L}$ aliquots were electrophoresed on $4 \%$ polyacrylamide, $7 \mathrm{M}$ urea denaturing gels run in $1 \times \mathrm{TBE}$ (Tris-borate-EDTA). Gels were imaged by autoradiography as described above. 
For in vitro transcriptions with T4 DNA, T4 genomic DNA was purified from concentrated T4 wt by extraction with phenol, phenol:chloroform:isoamyl alcohol (25:25:1), and then chloroform:isoamyl alcohol (24:1); each extraction step was repeated twice. The purified DNA was subsequently dialyzed against TE buffer, and then treated with T4 DNA ligase (New England Biolabs, Ipswich, MA, USA) in the presence of ATP to seal any intramolecular nicks. Transcription reactions $(100 \mu \mathrm{L})$ were assembled with 0.06 pmol of T4 DNA, 7.5 pmol pre-reconstituted RNAP (sigma:core ratio of 2.5:1), transcription buffer, and as indicated, $112.5 \mathrm{pmol}$ AsiA, 1.88 pmol MotA and/or 60 pmol DksA. After incubation at $37^{\circ} \mathrm{C}$ for $10 \mathrm{~min}$, a single round of transcription was initiated by adding heparin (final concentration of $100 \mu \mathrm{g} / \mathrm{mL}$ ) and rNTPs (final concentration of $200 \mu \mathrm{M}$ each ATP, GTP, CTP, UTP). Samples were incubated for $10 \mathrm{~min}$ at $37^{\circ} \mathrm{C}$ before collection on dry ice. An independent in vitro transcription reaction was performed as described [40] using pGEX-5X-3 DNA (0.05 pmol, Pharmacia Biotech, Piscataway, NJ, USA), which contains the Ptac promoter. Before RNA isolation, a $10 \mu \mathrm{L}$ aliquot of the Ptac reaction was added as an internal control into each sample, and then the RNA was extracted and purified by phenol extraction/ethanol precipitation as described above. $5^{\prime}$-ends of the RNA were detected by primer extension analyses as described above.

\section{Results}

\subsection{T4 Infections in the Absence of ppGpp or DksA Produce Larger Plaques}

Plaque size can be used as an indirect measure of phage fitness since larger plaques can arise from better phage growth. T4 wt infections of different $E$. coli wt strains typically yield plaques with similar sizes. For example, using two different E. coli B strains, B606 wt or BL21(DE3) wt, we observed similar T4 wt plaques with minimal heterogeneity (average size of $\sim 96$ pixels ${ }^{2}$ and $\sim 81$ pixels $^{2}$, respectively) (Figure S2a). In contrast, T4 wt infections of either B606 $\Delta d k s A$ (Figure 1a) or B606 ppGpp ${ }^{0}$ (Figure S2b) produced broad populations with both larger plaques and increased heterogeneity (average size of $\sim 147$ pixels $^{2}$ and $\sim 144$ pixels $^{2}$, respectively). An amber mutation in the T4 gene $\operatorname{mot} A\left(\mathrm{~T} 4 m o t A^{a m}\right)$ is known to significantly impair T4 infection due to a dramatic decrease in middle gene expression and delayed replication ([25,42]; reviewed in [23]). As expected, a T4mot $A^{\text {am }}$ infection produced significantly smaller plaques than a T4 wt infection of the same strain (Figure 1b vs. Figure 1a). Surprisingly, larger T4mot $A^{a m}$ plaques were observed with either B606 $\Delta d k s A$ (Figure 1b) or B606 ppGpp $^{0}$ (Figure S2c) (average size of $\sim 65$ pixels $^{2}$ and $\sim 39$ pixels $^{2}$, respectively) compared to B606 $\mathrm{wt}$ (average size of $\sim 7$ pixels $^{2}$ ).

Although B606 $\Delta d k s A$ grows more slowly than wt as cells enter stationary phase, we did not observe a marked difference in growth among wt, B606 $\Delta d k s A$ and B606 ppGpp ${ }^{0}$ during early to mid-log phase, when T4 infects (Figure S3). Consequently, we concluded that the differences in T4 plaque sizes did not arise from significantly different growth rates for the host strains.
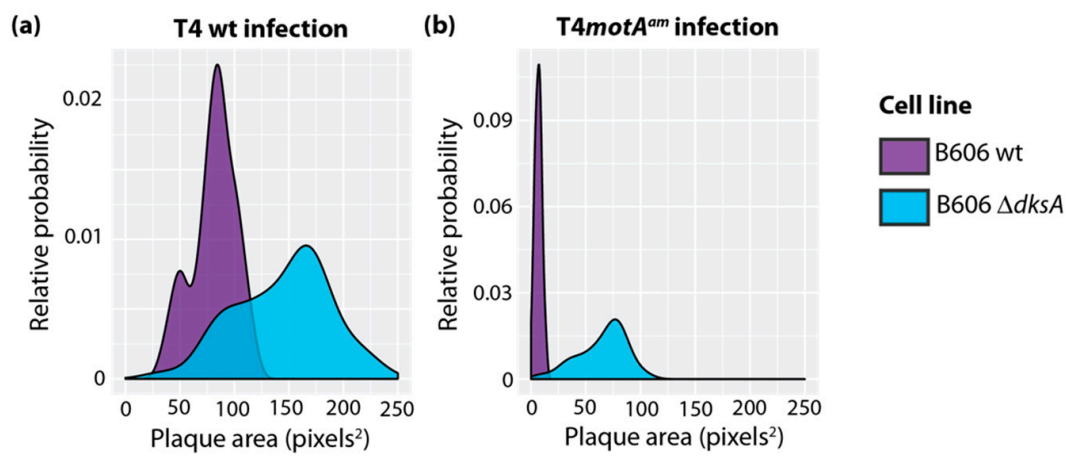

Figure 1. T4 infections in the absence of DksA produce larger plaques. Density plots of plaque size for B606 wild type (wt; purple) and B606 $\Delta d k s A$ (blue) infected with either T4 wt (a) or T4mot $A^{\text {am }}$ (b). Plots shown represent one of three biological replicates. 


\subsection{Deletion of $d k s A$ Results in an Increase in Phage Progeny per Infection}

Plaque size is affected by several factors, including the number of phage progeny (i.e., burst size), diffusivity, absorption rate, and length of the latent period [50,51]. To assess whether the larger plaque size observed in the absence of DksA or ppGpp arose from an increase in the number of phage progeny, we performed burst size experiments for T4 wt infections of B606 wt, B606 $\Delta d k s A$, and B606 ppGpp . $^{0}$ We found that the absence of DksA increased the burst size 2-fold (Figure 2a,b), while the absence of ppGpp had no statistically significant effect (Figure S4). In addition, we observed no drastic change in latent period for any of the infected strains (Figure 2a,c and Figure S4a). We conclude that the increase in plaque size for $\mathrm{T} 4 \mathrm{wt}$ in the absence of $\mathrm{DksA}$ can be attributed to an increase in phage progeny per infection. Conversely, the increase in plaque size in the absence of ppGpp is not related to burst size or latent period.
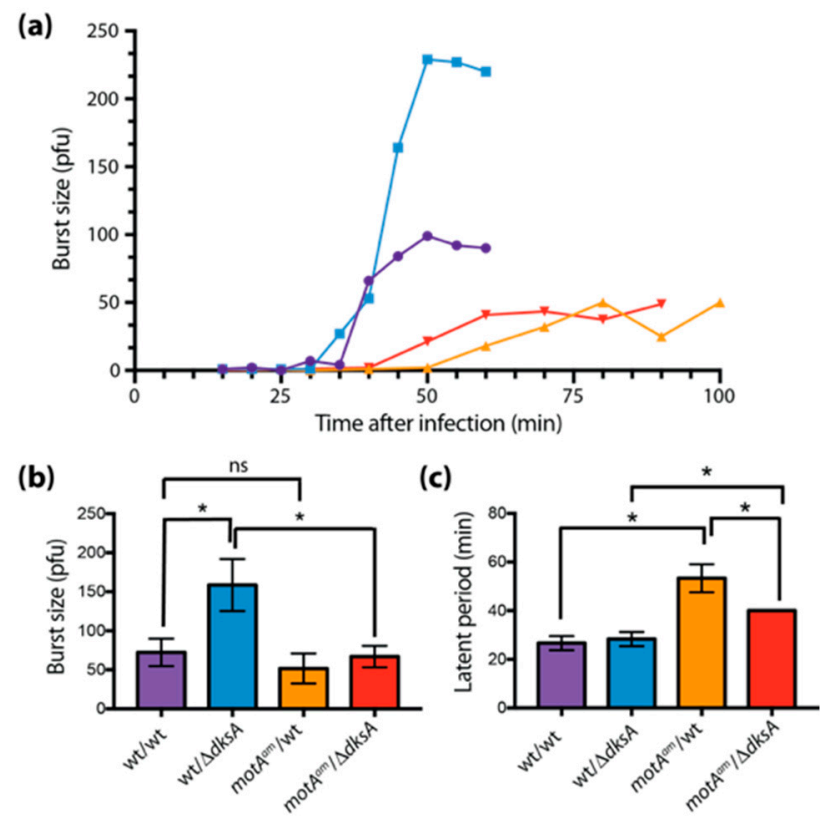

Figure 2. Absence of DksA increases the burst size of a T4 wt infection and decreases the latent period of a T4mot $A^{a m}$ infection. (a) Representative graph of burst size vs. time after infection; (b) burst size, and (c) latent period for infections of T4 wt/B606 wt (purple), T4 wt/B606 $\Delta d k s A$ (blue), T4mot $A^{a m} / \mathrm{B} 606$ wt (orange), and T4mot $A^{a m} / \mathrm{B} 606 \Delta d k s A$ (red). Averages with indicated standard deviations were determined as described in Materials and Methods from three independent replicates. (The error bar on $m o t A^{a m} / \Delta d k s A$ is too small to be visible.) Asterisks $\left(^{*}\right)$ indicate significance as determined by an unpaired t test with a $p$ value $\leq 0.05$. The apparent $5 \mathrm{~min}$ difference in latent period of the wt/wt and wt $/ \Delta d k s A$ infection shown in (a) is not statistically significant (see panel (c)).

\subsection{Deletion of $d k s A$ Results in a Shorter Latent Period in a T4mot $A^{\text {am }}$ Infection}

Similar burst size experiments were also performed with T4mot $A^{a m}$. In this case, we did not observe a significant difference in burst size for T4mot $A^{a m}$ in host wt vs. $\Delta d k s A$ strain (Figure 2a,c). However, in the absence of DksA, there was a 10 min decrease in the latent period, indicating a significantly faster infection (Figure $2 \mathrm{a}, \mathrm{c}$ ).

\subsection{Global Transcriptome of the T4mot $A^{a m}$ Infection Reveals that Pm's Are Differentially Affected}

To investigate the effect of DksA on gene expression in a T4 wt or T4mot $A^{a m}$ infection, we first collected detailed information on gene expression alterations in a T4mot $A^{\text {am }}$ infection of B606 wt. Although extensive work has established that $\operatorname{mot} A$ is required for activation of T4 middle promoters, a global transcriptome analysis of the mot $A$ regulon has not been reported. It should be noted that 
while a mot $A$ deletion is lethal [52], the T4mot $A^{a m}$ mutation is not. Nevertheless, there is a dramatic inhibition of transcription from MotA-dependent promoters and a DNA delay phenotype [40,42,52].

We therefore carried out RNA-seq to define the MotA regulon by comparing gene expression in $\mathrm{B} 606 \mathrm{wt}$ cells infected for $5 \mathrm{~min}$ at $37^{\circ} \mathrm{C}$ with either T4 wt or T4mot $A^{a m}$. At the 5 min infection point, middle genes were highly expressed, early transcription was ending, and late gene expression had initiated (reviewed in $[53,54]$ ). Genes, whose expression changed $\geq 2$-fold with a $p$ value $\leq 0.05$, were considered significant.

As shown schematically in Figure 3, the T4 genome is generally organized as regions of pre-replicative genes (early and middle) that are transcribed right-to-left and interrupted by regions of late genes that are transcribed left-to-right (reviewed in [53]). In general, early genes encode products needed for middle gene expression and to usurp host processes. However, the functions of many early genes are still unknown. Middle genes encode products needed for the crucial functions of replication, recombination, late gene transcription, and the continuation of host takeover. Late genes mainly encode morphological proteins. Since the majority of the T4 Pe's, Pm's, and Pl's have been identified (reviewed in $[23,53]$ ), we generated a detailed diagram of early, middle, and late transcription along the entire T4 genome (Figure 3). Convention within the field has provided designations for Pe's based on genomic coordinates (e.g., Pe15.0), whereas Pm's and Pl's are indicated by the first gene within the resulting transcript (e.g., Pm $d s b A$ and P115).

Previous global analyses of T4 gene expression using hybridization studies or levels of various phage proteins during a T4mot $A^{a m}$ infection have indicated that when MotA-dependent promoters are not activated, expression of some early genes remains high, while late transcription, which is dependent on the middle products gp55, gp33, and gp 45, is significantly diminished (reviewed in [54]). However, the expression of middle genes varies. This phenomenon arises in part because the effect of the mot $A$ knockdown on Pm activation is promoter specific $[40,42,55]$. In addition, most middle genes are transcribed by both Pm's and upstream Pe's (Figure 3). Therefore, the effect of T4mot $A^{a m}$ on a particular middle gene also depends on how much transcription from a Pe extends into this gene. While the mechanism for this elongation has not been fully elucidated, it appears to be dependent on processes that stabilize RNA rather than by anti-termination [56,57]. Even though the $3^{\prime}$ ends of many of these transcripts have been identified (indicated as grey bars in Figure 3), these ends are thought to represent the ends of the stable RNA rather than transcription termination sites.

Differential expressions determined by RNA-seq analysis were compared to RT-qPCR assays of 68 genes using RNA isolated 5 min after infection and by primer extension analyses using RNA isolated at 1 and $5 \mathrm{~min}$ after infection. One min after infection, early promoters are active, but middle transcription has just initiated $[53,54]$. A comprehensive summary of our RNA-seq and RT-qPCR analyses is shown in Figure 3. Overall, we observed a strong correlation between the results of the RNA-seq and RT-qPCR analyses (Figure S5a).

Not surprisingly, our RNA-seq/RT-qPCR analyses were consistent with the results from previous studies of T4mot $A^{a m}$ infections. Expression of $44 \%$ of early genes increased $\geq 2$-fold, while expression of $79 \%$ of late genes decreased $\geq 2$-fold (Figure 3). (Genes are classified according to the expression patterns observed in a previous global microarray analysis of a T4 wt infection [58].) Expression of middle genes was mixed, and middle genes that show significant MotA dependence varied in the magnitude of their dependence.

To confirm that changes in gene expression arose from defects in Pm transcription, primer extensions were performed for several middle genes (Figure S6a). As expected, this analysis confirmed previous results indicating that the $m o t A^{a m}$ mutation results in a significant decrease in Pm activation. In addition, we also observed lower transcription in the T4mot $A^{a m}$ infection that maps to one early promoter, Pe148.6 (Figure S6b). This result is surprising because the classification of this promoter as a Pe is confirmed by its activity $1 \mathrm{~min}$ after infection (Figure $4 \mathrm{~b}$, lanes $5-8$ ) and because there is no recognizable Pm sequence at this site. However, reduced transcription from Pe148.6 has also been observed in a T4mot $A^{a m}$ infection of another cell line [40]. 


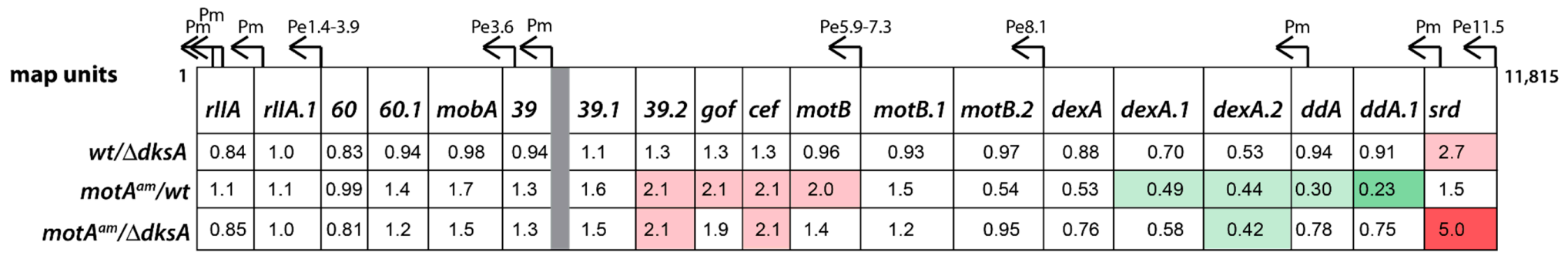

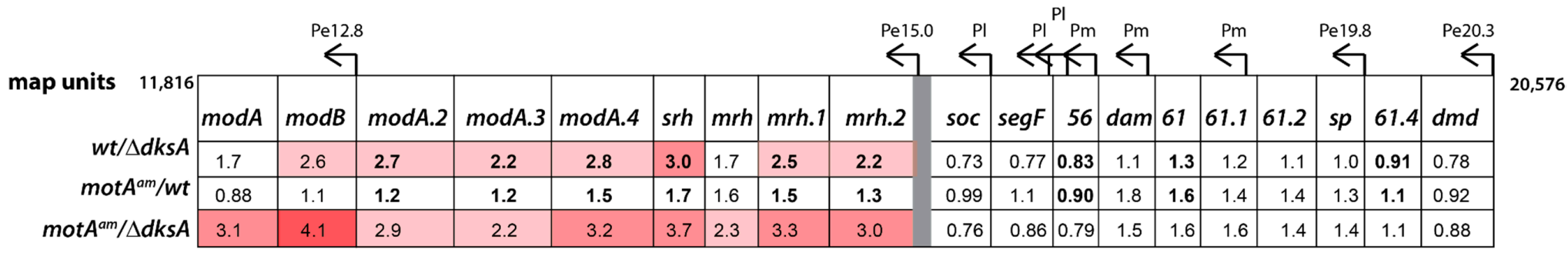

\begin{tabular}{|c|c|c|c|c|c|c|c|c|c|c|c|c|c|c|c|c|c|c|c|c|c|}
\hline \multirow{2}{*}{ lap units $\quad 20,577$} & \multicolumn{5}{|c|}{$\stackrel{P^{m}}{\hookrightarrow} \stackrel{P_{1}}{\leftarrow}$} & \multicolumn{2}{|c|}{$\stackrel{P m}{\zeta}$} & $\stackrel{\text { Pe26.4 }}{\rightarrow}$ & $\stackrel{P_{m}}{\zeta}$ & \multicolumn{4}{|r|}{$\stackrel{P m}{\leftrightarrow}$} & \multicolumn{4}{|c|}{$\stackrel{\substack{\mathrm{Pm} \\
\mathrm{Pm}}}{\mathrm{Pm} P \mathrm{~m}}$} & \multicolumn{3}{|c|}{$\stackrel{\text { Pe35.3 }}{\leftarrow} \stackrel{\text { Pm }}{\rightarrow}$} & \multirow[b]{2}{*}{$\alpha-g t$} \\
\hline & 41 & 40 & uvs X & $\operatorname{seg} A$ & $\beta-g t$ & 42 & $\mathrm{imm}$ & imm.1 & 43 & $\operatorname{reg} A$ & $\mid 62$ & 44 & 45 & $r p b A$ & 45.2 & 46 & 46.1 & 46.2 & 47 & 47.1 & \\
\hline$w t / \Delta d k s A$ & 0.70 & 0.76 & 0.76 & 1.1 & 1.1 & 1.0 & 1.2 & 0.66 & 0.58 & 0.66 & 0.72 & 0.72 & 0.69 & 0.81 & 0.57 & 0.68 & 0.44 & 0.61 & 0.60 & 0.49 & 0.64 \\
\hline$m o t A^{a m} / w t$ & 0.70 & 0.55 & 0.62 & 0.69 & 0.74 & $(0.76)$ & 0.93 & 0.20 & 0.04 & $(0.05)$ & 0.06 & 0.06 & 0.06 & 0.09 & 0.08 & 0.20 & 0.22 & 0.21 & 0.15 & 0.12 & 0.15 \\
\hline 然 & 0.64 & 0.61 & 0.61 & 0.83 & 0.97 & 0.99 & 1.4 & 0.40 & 0.06 & 0.08 & 0.09 & 0.11 & 0.10 & 0.17 & \begin{tabular}{|l|}
0.11 \\
\end{tabular} & 0.38 & 0.33 & \begin{tabular}{|l|}
0.41 \\
\end{tabular} & 0.29 & 0.23 & 0.31 \\
\hline
\end{tabular}

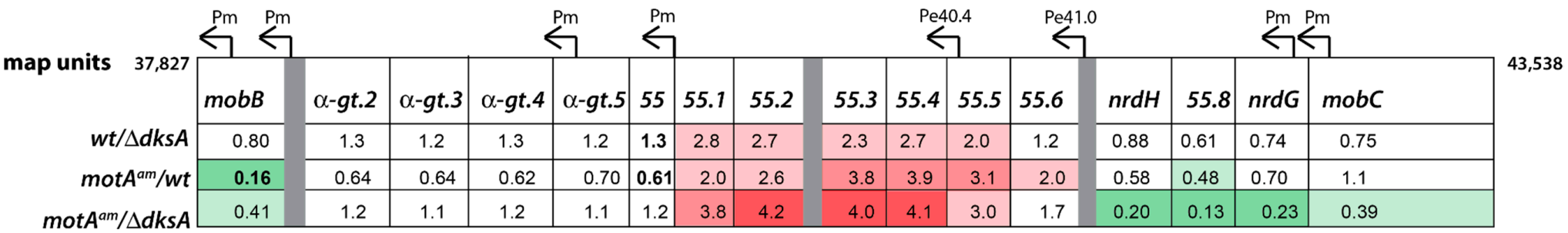




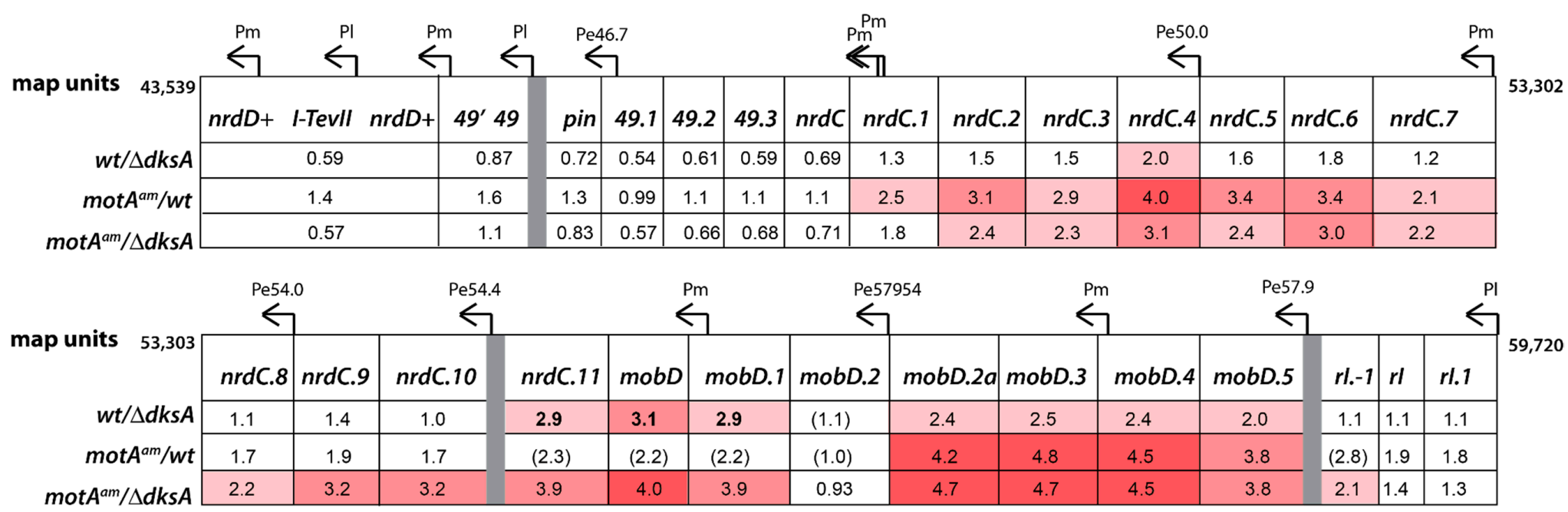

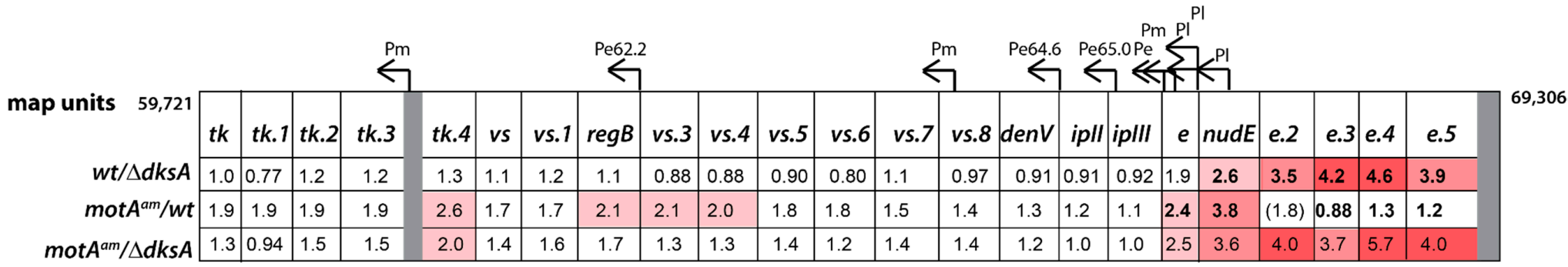

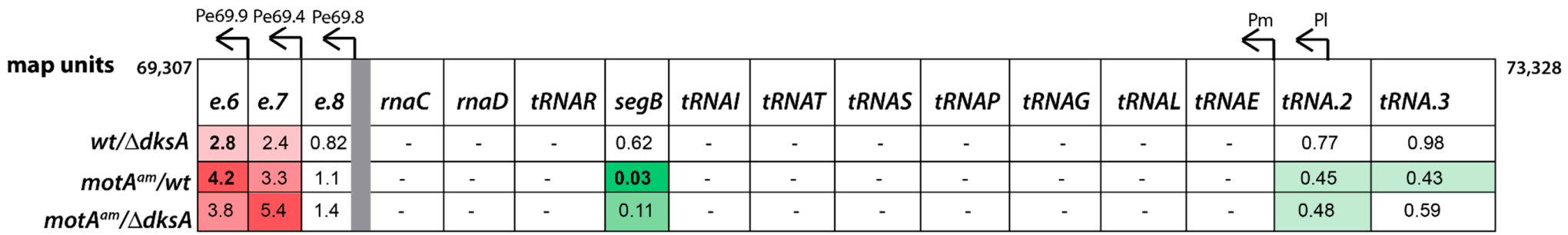




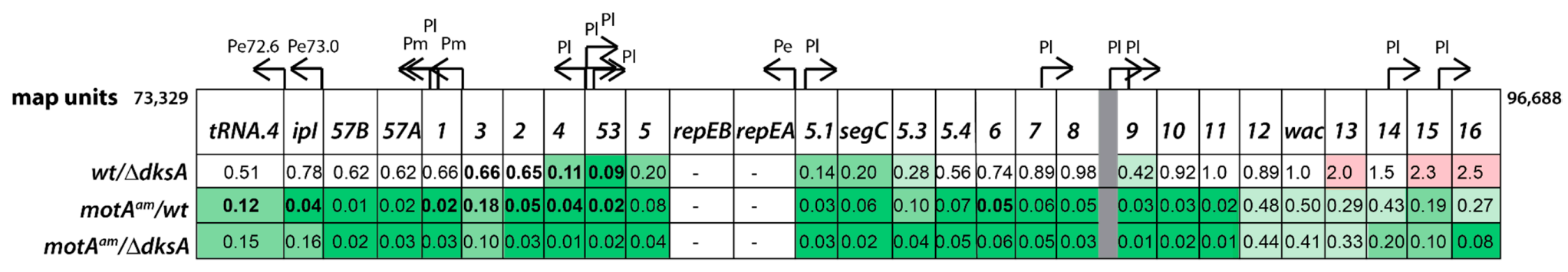

\begin{tabular}{|c|c|c|c|c|c|c|c|c|c|c|c|c|c|c|c|c|c|c|c|}
\hline \multirow{2}{*}{96,689} & \multicolumn{2}{|r|}{$\stackrel{P 1}{\longrightarrow}$} & \multicolumn{2}{|c|}{$\stackrel{\mathrm{Pl}}{\longrightarrow} \stackrel{\mathrm{Pl}^{\mathrm{PI}}}{\rightrightarrows}$} & \multicolumn{2}{|c|}{$\stackrel{\text { Pl }}{\longrightarrow} \stackrel{P I}{\longrightarrow}$} & \multicolumn{2}{|c|}{$\stackrel{\text { Pl }}{\longrightarrow}$} & \multicolumn{3}{|c|}{$\stackrel{P \mid}{P|P|}$} & $\stackrel{\mathrm{Pl}}{\longrightarrow}$ & \multicolumn{2}{|c|}{$\stackrel{P m}{\leftarrow}$} & $\stackrel{P_{m}}{\zeta}$ & \multicolumn{4}{|c|}{$\stackrel{\mathrm{Pm} P \mathrm{Pl}}{\stackrel{4}{\longrightarrow}} \stackrel{\mathrm{PI}}{\longrightarrow}$} \\
\hline & 17 & $\begin{array}{llll}17^{\prime \prime} A & 17^{\prime \prime}\end{array}$ & 18 & 19 & 20 & 67 & 68 & $2121^{\prime}$ & 22 & 23 & $\operatorname{seg} D$ & 24 & $r n / B$ & 24.2 & 24.3 & hoc & inh & $\operatorname{seg} E$ & uvsW \\
\hline$w t / \Delta d k s A$ & & 2.4 & 1.7 & 0.51 & 0.580 & 0.71 & 0.74 & 1.1 & 1.5 & 2.1 & 2.5 & 0.78 & 0.68 & 0.72 & $\overline{0.92}$ & 0.58 & 0.28 & 0.08 & 0.20 \\
\hline $\operatorname{mot} A^{a m} / w t$ & & 0.22 & 0.09 & 0.26 & $0.24 \mathrm{c}$ & & 0.31 & 0.24 & 0.190 & & 0.33 & 0.02 & 0.01 & 0.01 & 0.01 & 0.03 & 0.03 & 0.03 & 0.04 \\
\hline$t A^{a m} / \Delta d k s A$ & & 0.15 & 0.12 & 0.24 & 0.20 & & 0.25 & 0.44 & $0.47 \mathrm{C}$ & 0.80 & 0.99 & 0.02 & 0.01 & 0.01 & 0.02 & 0.02 & 0.01 & 0.01 & 0.01 \\
\hline
\end{tabular}

\begin{tabular}{|c|c|c|c|c|c|c|c|c|c|c|c|c|c|c|c|c|c|c|c|c|}
\hline \multirow[b]{2}{*}{ map units 114,473} & $\leftrightarrow^{P I}$ & \multicolumn{4}{|c|}{ 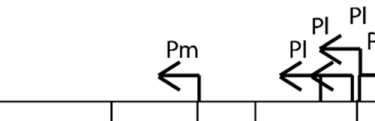 } & \multicolumn{10}{|c|}{$\stackrel{P e}{\hookrightarrow}$} & \multicolumn{3}{|c|}{$\stackrel{P m}{\leftarrow}$} & $\stackrel{P m}{\hookrightarrow}$ & \multirow[b]{2}{*}{$30.3^{\prime} 30.3$} \\
\hline & uvsY.-2 & uvs Y.-1 & uvsY & 25 & $26^{\prime} 26$ & 51 & 27 & 28 & 29 & 48 & 54 & alt.-3 & alt.-2 & alt.-1 & alt & alt.1 & 30 & 30.1 & 30.2 & \\
\hline$w t / \Delta d k s A$ & 0.52 & 0.53 & 0.51 & 0.31 & 0.19 & 0.21 & 0.37 & 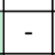 & & 1.3 & 0.84 & 1.2 & \begin{tabular}{|l|}
0.57 \\
\end{tabular} & 0.66 & 0.70 & 0.75 & 0.91 & \begin{tabular}{|l|}
1.1 \\
\end{tabular} & 0.97 & 1.6 \\
\hline$m o t A^{a m} / w t$ & 0.01 & 0.01 & 0.01 & 0.07 & 0.07 & 0.06 & 0.06 & & 0.57 & & 1.2 & 2.4 & 1.6 & 1.5 & 1.1 & 0.94 & 0.92 & 0.92 & 0.94 & 1.8 \\
\hline $\operatorname{mot} A^{a m} / \Delta d k s A$ & 0.01 & 0.01 & 0.01 & 0.03 & 0.01 & 0.02 & 0.06 & & 0.29 & 0.64 & 1.2 & 1.8 & 0.96 & 1.0 & 0.93 & 0.84 & 0.94 & 1.2 & 1.0 & 2.4 \\
\hline
\end{tabular}

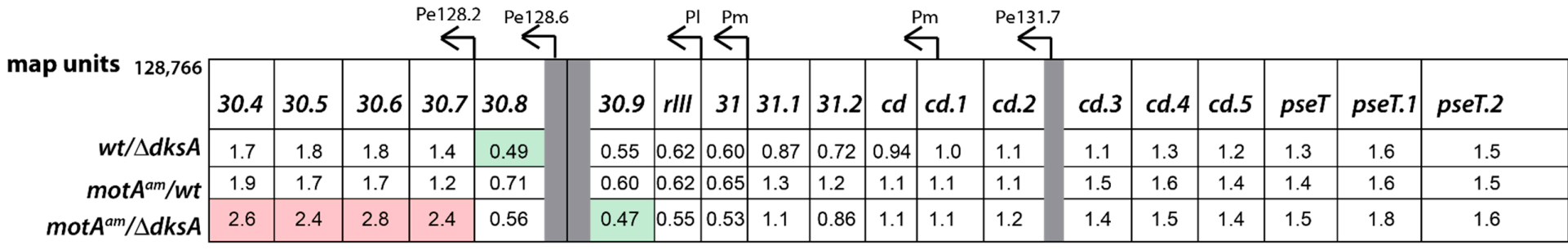




\begin{tabular}{|c|c|c|c|c|c|c|c|c|c|c|c|c|c|c|}
\hline \multirow[b]{2}{*}{ map units 135,432} & \multicolumn{3}{|c|}{$\stackrel{\mathrm{Pe} 134.4}{\leftarrow}$} & \multicolumn{4}{|r|}{$\stackrel{P m}{\leftarrow}$} & \multicolumn{4}{|c|}{$\stackrel{P m}{\leftrightarrow}$} & \multicolumn{3}{|c|}{$\stackrel{P l}{\leftrightarrow} \stackrel{P m}{\leftrightarrow}$} \\
\hline & pseT.3 & alc & $|r n I A|$ & $\operatorname{den} A$ & $n r d B+$ & I-TevIll $n r d B+$ & $n r d B .1$ & mobE & $n r d A$ & $n r d A .1$ & $n r d A .2$ & $t d+I-T e v l t d+$ & frd & frd.1 \\
\hline$w t / \Delta d k s A$ & 1.5 & \begin{tabular}{|l|}
1.5 \\
\end{tabular} & 0.74 & 0.75 & & 0.65 & 0.71 & 0.69 & 0.80 & 1.1 & 1.2 & 1.2 & 2.3 & 2.1 \\
\hline$m o t A^{a m} / w t$ & 1.5 & 1.6 & 0.68 & 1.4 & & 0.87 & 0.98 & 1.3 & 1.2 & 0.97 & 1.5 & 1.1 & 2.7 & 1.6 \\
\hline$m o t A^{a m} / \Delta d k s A$ & 1.6 & 1.8 & $|0.17|$ & 0.44 & & 0.44 & 0.68 & 0.88 & 0.98 & 1.1 & 1.4 & 1.5 & 4.2 & 3.4 \\
\hline
\end{tabular}

146,051

\begin{tabular}{|c|c|c|c|c|c|c|c|c|c|c|c|c|c|c|c|c|c|c|c|c|c|}
\hline & & Pe144. & ${ }_{\mathrm{Pl}}^{\mathrm{PI}} \leqslant$ & & & & & 148.6 & $\mathrm{PI} \mathrm{Pm}$ & & & & & $\mathrm{PI}_{2}$ & $\stackrel{P e 15}{\longleftarrow}$ & & & & & & \\
\hline & frd.2 & frd.3 & 32 & $\operatorname{seg} G$ & 59 & 33 & $d s b A$ & $r n h$ & 34 & 35 & 36 & 37 & 38 & $t$ & asiA & asiA.1 & arn & arn.1 & arn.2 & arn.3 & arn.4 \\
\hline$w t / \Delta d k s A$ & 1.8 & 1.0 & 0.68 & 0.87 & 0.94 & 0.85 & 0.86 & 1.1 & 1.0 & 0.87 & 0.52 & $(0.75)$ & 2.7 & 2.4 & 1.3 & 1.4 & 1.5 & 1.7 & 1.7 & 1.8 & 1.7 \\
\hline $\operatorname{mot} A^{a m} / w t$ & (4.6) & 1.5 & 0.02 & 0.03 & 0.03 & 0.05 & 0.07 & 0.14 & $0.06 \mid$ & 0.08 & 0.12 & (0.58) & 3.1 & 3.2 & 3.2 & 3.0 & 3.2 & 3.2 & 2.9 & 2.3 & 2.1 \\
\hline $\operatorname{mot} A^{a m} / \Delta d k s A$ & 4.5 & 2.2 & 0.11 & 0.17 & 0.21 & 0.21 & 0.26 & 0.58 & 0.07 & 0.06 & 0.18 & 0.98 & 6.5 & 5.3 & 2.1 & 2.2 & 2.2 & 2.7 & 2.8 & 3.1 & 3.2 \\
\hline
\end{tabular}

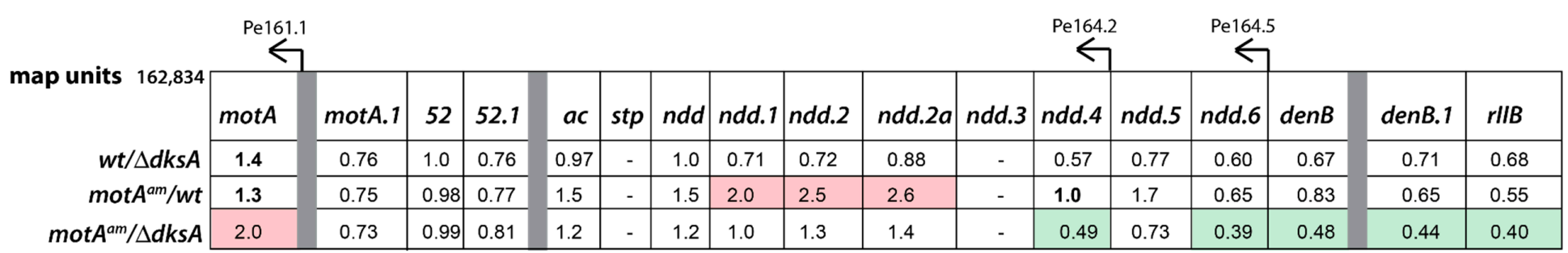

Figure 3. Genomic map of bacteriophage T4 correlated with gene expression data from RNA-seq. Graphical representation of the T4 genome showing the location of annotated genes and promoters as given in [53]. The fold changes from the RNA-seq analyses determined for infections of T4 wt/B606 dks $A$ (wt/dks $A$ ), T4mot $A^{a m} / \mathrm{B} 606$ wt $\left(m o t A^{a m} / \mathrm{wt}\right)$, and T4mot $A^{a m} / \mathrm{B} 606 \Delta d k s A\left(m o t A^{a m} / d k s A\right)$ compared to T4 wt/B606 wt are indicated. Gene expression changes are color coded as: increasing expression $\geq 2.0$ with increasing red intensity; no significant change, white; decreasing expression $\leq 0.5$ with increasing green intensity. Values of genes whose expression was checked by real-time quantitative polymerase chain reaction (RT-qPCR) are given in bold; any value that was tested in RT-qPCR analyses but was not consistent is given in parenthesis. Genes without an indicated value had less than 50 mapped reads in all the RNA-seq data samples. The genomic coordinates (map units) for each region are listed at the start and end of that row of genes. 
(a)

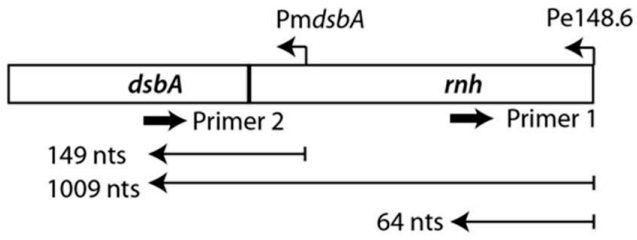

(b)

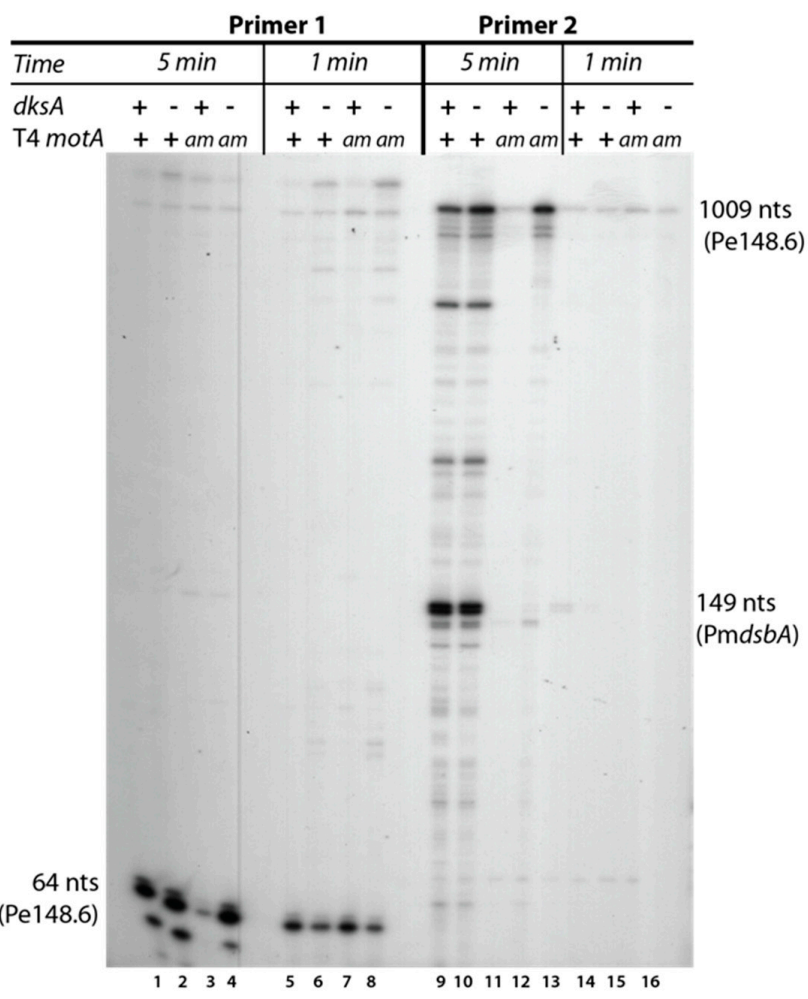

Figure 4. RNA from Pe148.6, which is significantly reduced in a T4mot $A^{a m}$ infection of B606 wt at 5 min post-infection, is rescued by a deletion of DksA. (a) Schematic showing T4 map units from 150,727 to 149,509 containing genes $r n h$ and $d s b A$ with the relative positions of the early promoter Pe148.6 and the middle promoter Pm $d s b A$ and the primers used for primer extension analyses. Sizes of the expected primer extension products are indicated in nts; (b) Representative gel showing the primer extension products from primers indicated in panel (a). RNA was isolated from T4 wt (+) or T4mot $A^{a m}$ (am) infections of strain B606 wt (+) or B606 $\Delta d k s A(-)$ at 5 or 1 min post-infection.

Overall, these analyses provided a "proof of principle" that our RNA-seq analyses correctly reflected the state of T4 transcription 5 min post-infection. However, this study also significantly extended previous work because one can now investigate the effect of the mot $A$ knockdown on each gene throughout the T4 genome. Interestingly, our results indicate that there did not appear to be any general correlation between the function of a middle gene and its dependence on MotA. As seen in Figure 3, within regions that contain both Pe's and Pm's, we observed two sections of T4 genes that are crucial for replication and late transcription and are highly dependent on MotA: (1) the region downstream of Pe35.3 (map units 35,662 to 27,197) that includes gene 43 (DNA polymerase), gene 45 (DNA polymerase clamp and late transcription enhancer), and genes 44/62 (clamp loader) and (2) the region downstream of Pe148.6 (map units 150,727 to 146,948) that includes gene 33 (co-activator required for late transcription), $r n h$ (RNase H), gene 59 (DNA helicase loader for replication), and gene 32 (single-stranded DNA binding protein). However, other sections with $\mathrm{Pe}^{\prime} \mathrm{s}$ and Pm's, whose genes also encode important replication and late transcription factors, were not significantly MotA-dependent. These included: (1) the region downstream of Pe26.4, Pe20.3, and Pe19.8 
(map units 27,044 to 17,935) containing genes 41/61 (DNA helicase/primase) and uvsX (recA analog), and (2) the region downstream of Pe40.4 (map units 41,225 to 39,600) containing gene 55 (sigma factor for late transcription). Because the Pm's for both these regions (Pm55 and PmuvsX) are highly dependent on MotA (Figure S6a), we conclude that it is the extension of Pe's into these regions that compensates for the lack of MotA.

Thus, our analyses indicate that at 5 min post-infection in the mot $A$ knockdown, the expression of only a subset of middle genes encoding replication/recombination proteins was near wt levels. These include the genes for helicase (gp41), the recombination protein UvsX, EndoVII (gp49) that resolves recombination structures, nucleases gp46 and gp47, and DNA ligase (gp30). Such a combination of proteins suggests a minimal system for recombination in which nucleases $46 / 47$ might generate ssDNA substrates suitable for homologous recombination by UvsX/gp41. The nicked DNA would then be sealed by DNA ligase. However, whether such a system is used is not known.

Unexpectedly, RNA-seq indicated that the expression of two late genes, $t$ (holin, map units 160,221 to 160,877 ) and 38 (catalyzes assembly of distal tail fibers, map units 159,649 to 160,200), increased in the T4mot $A^{a m}$ infection (Figure 3). We confirmed increased levels for both by RT-qPCR (Figure S5a). Given the significantly reduced levels of expression of T4 genes 45 and 33, whose products are required for late transcription, this result suggests an unusual expression mechanism for these late genes.

\subsection{Reduction of Early Promoter Activity during T4 wt Infection in the Presence of DksA}

Having established that the RNA analyses of T4 wt vs. T4mot $A^{a m}$ infections yielded expected results, we investigated gene expression in T4 infections of B606 wt or B606 $\Delta d k s A$ to ask whether DksA reduction of T4 progeny is related to T4 gene expression.

In a T4 wt infection at $5 \mathrm{~min}$, the absence of DksA resulted in a 2-fold or greater increase in expression of genes downstream of several Pe's: Pe11.5, Pe12.8, Pe15.0, Pe40.4, Pe57954, Pe57.9, Pe69.9, and Pe69.4 (Figure 3). Only a small subset of the genes in these regions have been functionally characterized. The genes that have been characterized to date have been implicated in host takeover through modification of transcriptional machinery $(\bmod A, \bmod B, s r h, \operatorname{mrh})$ or degradation of host nucleic acid ( $m o b D, n u d E)$ [53]. RNA-seq was performed for the $5 \mathrm{~min}$ samples and RT-qPCR was used to independently assess the differential expression of 49 selected genes. The fold changes determined by RT-qPCR demonstrated a strong correlation with those determined by RNA-seq, thus confirming results of the RNA-seq analysis (Figure S5b). In addition, primer extension analyses were performed for RNA isolated at 1, 5, and 12 min post-infection. Primer extension analyses also revealed a significant increase in transcription from Pe35.3, Pe40.4, and Pe41 (Figure S6b). In contrast, transcription from Pm's was unaffected or only very modestly affected (Pm45, Pm45.2) by the absence of DksA (Figure S6a). The increase in Pe transcription was not general. For example, no significant increase was observed for Pe148.6 (Figure S6b) and Pe144.6 (Figure S7), two Pe's whose downstream gene expression levels also did not increase in the RNA-seq analysis (Figure 3).

Somewhat surprisingly, the expression level of several late genes (Figure 3) and the level of transcription from the corresponding Pl's (Figure S7a) was significantly less at 5 min post-infection in the absence of DksA. Since this result is not compatible with an increase in burst size, we asked whether this decrease in late transcription was reversed at $12 \mathrm{~min}$ post-infection, when the level of late transcription in a wt infection is high. Primer extension analyses revealed that the level of RNA from these and other selected late promoters recovered well by this time point (Figure S7b).

Taken together, our results are consistent with a role of DksA in lowering the burst of $\mathrm{T} 4 \mathrm{wt}$ phage in a wt infection by decreasing the level of transcription from many Pe's. As mentioned above, the function of many early genes remains unknown. However, these early genes are predicted to be involved in host takeover and transition to middle gene expression [53]. It is plausible that a fitness gain early in infection will cascade to increased progeny production as the infection progresses. 


\subsection{Middle Gene Expression is Partially Restored in a T4mot $A^{\text {am }}$ Infection of B606 $\Delta d k s A$}

The absence of DksA alleviated the poor growth of T4mot $A^{a m}$ by significantly decreasing the latent period (Figure 2). To determine if DksA affects gene expression in the T4mot $A^{a m}$ infection, RNA-seq, RT-qPCR, and primer extension analyses were performed after isolating RNA from T4mot $A^{\text {am }}$ infections in the presence (B606 wt) or absence (B606 $\Delta d k s A)$ of DksA.

The overall result of these analyses is that the DksA deletion partially ameliorates the poor expression of many T4 middle genes through the increase in transcription from certain Pe's. This result is most easily seen in Figure 3, in which expression levels of T4 genes are color coded to designate the extent of increase (shades of red) or decrease (shades of green). For example, in regions whose pre-replicative RNA levels were severely depressed in the T4mot $A^{\mathrm{am}} / \mathrm{wt}$ infection (the region containing genes $43,44,62$, and 45 (map units 32,662 to 27,197) and the region containing genes 33, $r n h, 59$, and 32 (map units 150,727 to 146,948)), the level of RNA from the T4mot $A^{a m}$ infection in the absence of DksA increases from 1.5 to 7 -fold over that seen in the T4mot $A^{a m}$ infection in the presence of DksA. These are the middle genes that are most severely affected by the mot $A$ knock-down.

Because the absence of DksA also increases the level of $\operatorname{mot} A$ transcription in the $\operatorname{mot} A^{a m}$ background by $\sim$-fold (Figure 3) and the $m o t A^{a m}$ mutation is leaky, some of this increase could arise from an increase in MotA protein, which could then lead to more Pm activation. However, it might also arise from the increase in transcription from Pe's, which then extends into downstream middle genes. To observe early and middle transcription separately, we used primer extension analyses.

We found that for the region containing map units 35,014 to 30,342 increased transcription from Pe35.3 in the absence of DksA was particularly helpful in counter-acting the effect of the mot $A$ knock-down since we observed no significant increase in middle transcription from Pm 46 or Pm 45 (Figures S6 and S8). Likewise, in the rnh-32 region (map units 150,727 to 146,948), we observed that the overall increase in transcription resulted from a significant increase in transcription from Pe148.6 rather than an increase in PmdsbA (Figure 4 and Figure S6b). In this case, a low level of Pe148.6 RNA was observed in the T4mot $A^{a m}$ infection of B606 wt at 5 min (Figure 4). However, the level of Pe148.6 RNA returned to that seen in the T4 wt/B606 wt infection when the motA knockdown was combined with the absence of DksA (Figure 4 and Figure S6b).

Unlike the middle genes detailed above, the transcript level of gene 55 (late sigma factor; map units 40,157 to 39,600 ) was not significantly reduced by the mot $A$ knockdown, yet gene 55 expression increased even more in a T4mot $A^{a m}$ infection in the absence of DksA (Figure 3). Primer extensions indicate that increased transcription of 55 is coming from Pe40.4 rather than from Pm55 (Figures S6, S8c and S8d). In addition, primer extensions revealed that Pe40.4 RNA is processed at map unit 40,902. This position contains the consensus sequence recognized by $\operatorname{RegB}$, a T4-encoded sequence-specific endonuclease that inactivates T4 early transcripts shortly after infection [59,60]. The transcript levels near (Figure S6b) and downstream (Figure S8d) from Pe40.4 were similar, indicative of regulation at or near the promoter either directly or indirectly by DksA.

No novel primer extension products were observed in any of the tested regions in the absence of DksA (Figure 4 and Figure S8), indicating that the deletion of DksA does not generate new transcription starts. As genes in regions transcribed by Pe35.3 (map units 35,662 to 27,197), Pe40.4 (map units 41,225 to 39,600 ), and Pe148.6 (map units 150,727 to 146,948) are required for replication and late transcription, it is not surprising that an increase in transcription from these promoters in the absence of DksA would improve the growth of the T4mot $A^{a m}$ phage in B606 $\Delta d k s A$ relative to $\mathrm{B} 606 \mathrm{wt}$.

\subsection{DksA Does Not Inhibit T4 Pe Transcription In Vitro}

Our results suggested that host protein DksA might directly down-regulate the activity of T4 Pe's. Although DksA regulated promoters often have AT- or GC-rich sequences within the -4 to -6 region (called the discriminator) that are needed for DksA action [61,62], a comparison of the sequences of down-regulated and unchanged Pe's revealed no obvious sequence motif that typically correlates with DksA modulation of transcription (Patterson-West and Hinton. NIDDK, Bethesda, MD. Comparison of 
promoter sequences, 2017.). To ask whether DksA inhibited Pe transcription directly, we first purified DksA and tested its previously characterized activity to inhibit the ribosomal promoter PrrnB1. As seen in Figure S9, addition of DksA specifically inhibited PrrnB1 but did not affect transcription from a control $\sigma^{70}$-dependent promoter (PS17). As expected, the presence of ppGpp improved this inhibition. Next, we performed in vitro transcription reactions using T4 DNA under the same buffer conditions. We assayed for transcription from specific Pe's using primer extension (Figure 5). DksA did not inhibit transcription from any of the tested Pe's that we previously showed were affected by the presence of DksA in vivo: Pe40.4 or Pe41 (Figure 5a), Pe35.3 (Figure 5b), or Pe148.6 (Figure 5c). The presence of DksA also did not affect transcription from the middle promoters PmdsbA (Figure 5c) or Pm46 (Figure 5b). It is important to note that the overall level of MotA/AsiA-activated transcription in this in vitro system was low because of the use of buffer conditions suited for DksA. We speculate that DksA reduction of specific Pe activity is either indirect or requires additional factors/conditions that were not present in our in vitro transcription system.

(a)

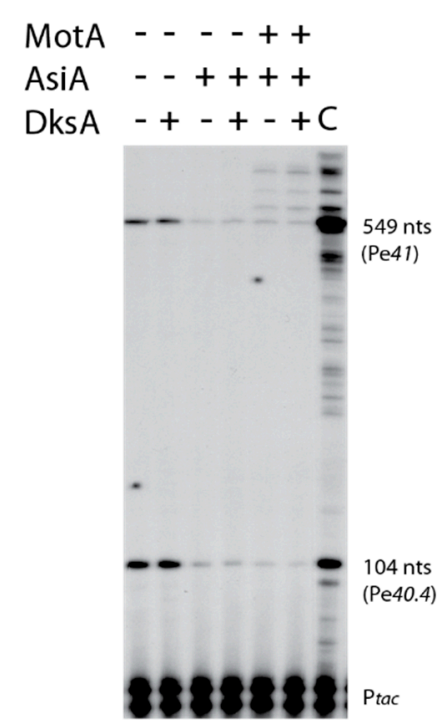

(b)

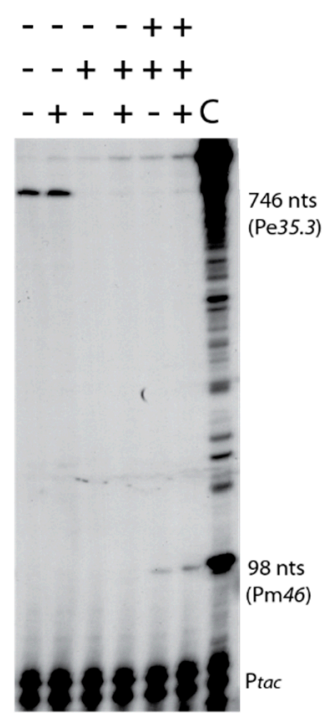

(c)

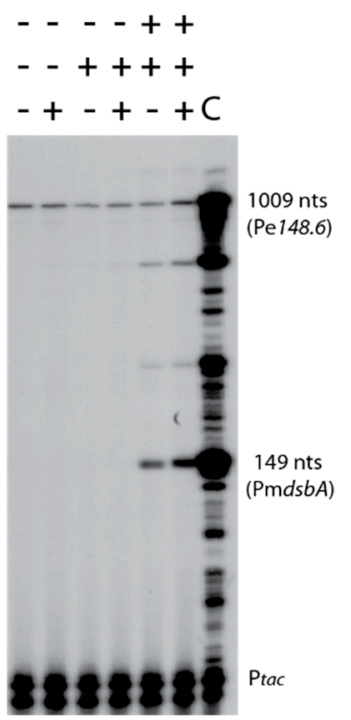

Figure 5. Presence of DksA has no effect on transcription from various T4 Pe's in vitro. Representative gels show primer extension products for Pe40.4 (a), Pm46 (b), and PmdsbA (c) arising from in vitro transcription of T4 wt DNA in the presence of DksA, MotA, and/or AsiA, as indicated. Each primer extension reaction also contained Ptac RNA and its primer as an internal control. In vivo RNA isolated from a T4 wt infection of B606 wt at 5 min post-infection was used as a positive control for each primer (labeled as lane C). The lengths of primer extension products are indicated in nt.

\subsection{Deletion of ppGpp Has Only Modest Effects on T4 Transcription}

Although the absence of either DksA or ppGpp results in larger T4 plaques (Figure 1a and Figure S2b), the lack of DksA increases burst size by 2-fold (Figure 2b) while the absence of ppGpp has no significant effect on burst size or latent period (Figure S4). Our RNA-seq analyses of a T4 wt infection of a $\mathrm{B} 606 \mathrm{ppGpp}^{0}$ strain revealed only eight $\mathrm{T} 4$ genes whose expression changed significantly, while in the T4/ $\Delta d k s A$ infection, the expression of $>50$ genes were altered (Tables S1 and S2).

\section{Discussion}

DksA, a transcriptional regulator that modulates gene expression in E. coli at the levels of transcription initiation [63] and elongation [15,64], belongs to a family of proteins that can insert themselves into the $2^{\circ}$ channel of RNAP, the channel from which rNTPs enter the active site. The best characterized system of DksA regulation is stress response: the repression of ribosomal promoters 
and the activation of promoters for amino acid biosynthesis genes during amino acid starvation [65]. Both inhibition and activation typically involve the small molecule ppGpp [21], whose level rises dramatically during stress response, even as the level of DksA remains relatively constant [13,14]. For instance, the presence of ppGpp significantly improves the ability of DksA to inhibit initiation from ribosomal promoters [13].

DksA is a key player in bacterial survival under various environmental changes. For instance, $\Delta d k_{s} A$ Salmonella enterica is hyper-susceptible to the bacteriostatic effects of nitric oxide free radicals and is attenuated in macrophage and murine models of infection $[66,67] ; \Delta d k s A$ Shigella flexneri has decreased Hfq transcription, causing the loss of virulence [68]; and in E. coli, DksA has been shown to be important for survival of dehydration [69]. More recently, various studies have shown that DksA provokes global changes in transcriptional expression in host cells under various stresses, such as nitrosative, oxidative and nutrient stresses [70,71].

To our knowledge, no study has reported whether DksA contributes defense systems by modulating gene expression of phages during infection. Bacteriophage T4 is a good model system for investigating this since it primarily regulates gene expression at the level of transcription. Temporal gene expression by $\mathrm{T} 4$ is controlled by the recognition of three distinct promoter architectures (early, middle, and late). Pe's contain very strong $\sigma^{70}$ consensus sequences ( -10 and -35 elements) that are immediately recognized by the host transcriptional machinery [23,72]. Pm's and Pl's require viral-encoded factors to modify the sequence specificity of host RNAP. Middle genes are expressed approximately 1 to 2 min post-infection at $37^{\circ} \mathrm{C}$ by the activation of Pm's and/or extension of transcripts from Pe's (reviewed in [23]). Activation of Pm's requires two T4 early proteins, MotA and AsiA, which together modify the specificity of host RNAP $/ \sigma^{70}$ holoenzyme, allowing it to recognize a specific -30 sequence (the MotA box) rather than the host -35 element. Late transcription is initiated approximately 5-7 min after infection by the activation of Pl's. These promoters do not contain either the bacterial - 35 element or the MotA box sequence, but instead contain a novel - 10 sequence, known as the late TATA box, that requires a new sigma factor encoded by T4 gene 55, as well as the activator encoded by gene 33 [24]. In addition, late transcription requires active T4 DNA replication through the activity of the T4 protein gp45, which is the replication sliding clamp that also serves as an enhancer of late transcription [24].

The major finding of this study is that host protein DksA down-regulates the activity of Pe's, thereby limiting the number of progeny produced during a single infection. Consequently, DksA serves to suppress T4 infection. Increased transcription from specific Pe's in the $\Delta d k s A$ strain also explains the increased growth of T4mot $A^{a m}$ (Figure 1b). It has been well established that T4mot $A^{a m}$ severely impairs phage infection by depressing middle transcription. We observe that the improved fitness of T4mot $A^{a m}$ in the $\Delta d k s A$ strain correlates with a greater abundance of middle RNA. However, this increase in middle transcripts does not arise from Pm's, but rather from increased transcription from Pe's upstream of middle genes required for replication, recombination, and late transcription (Figure 3). Thus, the increase in Pe transcription compensates for the lack of Pm activation.

Presently, it is unclear how DksA exerts an effect on specific Pe's. The results of our in vitro transcription analyses argue that this effect is probably indirect. A comparison of the discriminator region [61,62] of Pe's whose transcripts were down-regulated vs. those whose transcripts were unchanged does not reveal an obvious sequence motif that typically correlates with DksA reduction of promoter activity. We speculate global host changes that arise from deletion of DksA are likely to be responsible for the enhancement of T4 Pe transcription. In fact, global changes in gene expression during exponential growth have been previously reported for $\Delta d k s A$ [21]. It is important to note, however, that we do not observe a major growth defect in B606 $\Delta d k s A$ during early-exponential phase at the time of T4 infection. Instead the growth defect is seen during stationary phase (Figure S3). This is likely due to decreased rpoS expression in the $\Delta d k s A$ mutant [73], which regulates expression of genes important for the transition into stationary phase. 
Although the absence of either DksA or ppGpp results in larger T4 plaques (Figure 1a and Figure S2b), the lack of DksA increases burst size by 2-fold (Figure 2b) and has dramatic effects on T4 gene expression, while $\mathrm{ppGpp}^{0}$ has no significant effect on burst size or latent period (Figure S4) and has only modest effects on gene expression (Table S2). In the host, ppGpp functions predominately at the level of transcription to adjust gene expression as necessary to overcome stress and to minimize processes that have become superfluous by growth inhibition. Cells that are ppGpp deficient for lack of spoT and relA genes become vulnerable to a variety of physiological stress conditions. As a result, $\mathrm{ppGpp}^{0}$ cells devote all resources to a full complement of biosynthetic capacity including ribosome content regardless of nutritional adequacy [74]. Since T4 phage infection almost instantly pirates cellular biosynthetic functions and components to devote them exclusively to phage production, perhaps it can be expected that phage development would improve in the absence of ppGpp. Deficiency of ppGpp could alter plaque size without altering burst size, latent period, and/or transcription because plaque size is also governed by properties of inner membranes, peptidoglycan and outer membranes, and the activities of pinholins and spanin complexes (reviewed by [75]). In fact, there is evidence of involvement of ppGpp in altered membranes and phospholipid synthesis that can result in membrane fragility $[76,77]$.

The enigmatic absence of regulatory effects associated with ppGpp might indicate the need for different conditions to detect effects of ppGpp on T4 burst size and latent period. For example, slow growth in minimal medium with a poor carbon source, which elevates the level of ppGpp, might give different results than a rich nutrient broth where the cellular ribosomal content is high and the ppGpp concentration is very low at the onset of infection. It also might be revealing to measure ppGpp levels during phage T4 lytic development to evaluate if ppGpp levels change. Alternatively, ppGpp levels could be artificially elevated to high levels at the onset of T4 infection to ask if development is altered.

Host factors that regulate viral transcription during phage infections have been reported for multiple systems. In several cases, phage-encoded proteins that modulate the functions of these bacterial regulators have also been observed. These include the E. coli transcription terminator Rho and lambdoid phage antiterminators, $\mathrm{N}$ and $\mathrm{Q}$ (reviewed in [78]). In addition, bacterial histone-like proteins, such as H-NS in E. coli, can repress viral transcription (reviewed in [79]). Interestingly, the T7 protein gp5.5 [80], the T4 protein Arn [81], and the phage LUZ24 protein MvaT [82] have each been shown to inhibit H-NS repression through distinct mechanisms. Future work investigating the effects of bacterial transcriptional regulators will likely reveal additional host proteins that regulate viral gene expression. Understanding the role of ppGpp, DksA, and other E. coli factors that regulate transcription and transcription/translation coupling, such as GreA and NusG, may reveal new mechanisms required for host takeover and identify new functions of additional viral proteins.

Supplementary Materials: The following are available online at http:/ /www.mdpi.com/1999-4915/10/6/308/s1, Figure S1: DksA-His 6 is highly purified, Figure S2: T4 infections of B606 ppGpp ${ }^{0}$ produce larger plaques, Figure S3: Minor growth differences between wt and mutant strains during early exponential phase, Figure S4: Absence of ppGpp does not affect burst size or latent period of a T4 wt infection, Figure S5: There is a strong correlation between the relative level of RNA determined by RNA-seq and RT-qPCR, Figure S6: The absence of DksA increases the level of transcription from T4 Pe's in a T4 wt and a T4mot $A^{a m}$ infection at 5 min post-infection, Figure S7: Transcription from late promoters is lower in the absence of DksA $(\Delta d k s A)$ compared to B606 wt at $5 \mathrm{~min}$ post-infection but returns to values near B606 wt levels by $12 \mathrm{~min}$ post-infection, Figure S8: Increased levels of middle genes 46 and 55 in T4mot $A^{a m}$ infections of cells lacking DksA $(\Delta d k s A)$ are due to increased levels of transcripts from an upstream early promoter at 5 min post-infection, Figure S9: Purified DksA inhibits PrrnB1 transcription in vitro, Table S1: Summary of all RNA-seq and RT-qPCR data, Table S2: Summary of genes that are differentially expressed in T4 wt infections of $\Delta d k s A$ and ppGpp ${ }^{0}$ compared to wt $E$. coli.

Author Contributions: J.P.-W., T.D.J., L.F.-C., K.M., M.C., and D.M.H. conceived and designed the experiments; J.P.-W., T.D.J., J. R. I., L.F.-C., K.M., and L.K. performed the experiments; J.P.-W., T.D.J., L.F. -C., K.M., L.K., M.C., and D.M.H. analyzed the data and wrote the paper. 
Acknowledgments: We thank M. Hsieh, M. Arroyo-Mendoza, D. Lewis, and D.D. Kim for helpful discussion; D. Schneider for B606; D.D. Nogare for assistance and technical expertise for ImageJ workflow development; and the NICHD genomics core for library construction, sequencing, and bioinformatics analysis. We are grateful to S. Morrical and S. Nelson for helpful discussions about T4 recombination. This Research was supported by the Intramural Research Program of the NIH, National Institute of Diabetes and Digestive and Kidney Diseases (J.P.W., K.M., L.K., and D.M.H), by the NIH, Eunice Kennedy Shriver National Institute of Child Health and Human Development (L.F.C., T.D.J., J.R.I. and M.C.), and by the National Institute of General Medical Sciences of the National Institutes of Health under award number R43GM113546 (T.D.J.).

Conflicts of Interest: The authors declare no conflict of interest.

\section{References}

1. Lopez-Maury, L.; Marguerat, S.; Bahler, J. Tuning gene expression to changing environments: From rapid responses to evolutionary adaptation. Nat. Rev. Genet. 2009, 10, 68. [CrossRef]

2. Clokie, M.R.; Millard, A.D.; Letarov, A.V.; Heaphy, S. Phages in nature. Bacteriophage 2011, 1, 31-45. [CrossRef] [PubMed]

3. Keen, E.C. A century of phage research: Bacteriophages and the shaping of modern biology. Bioessays 2015, 37, 6-9. [CrossRef] [PubMed]

4. Brussow, H.; Canchaya, C.; Hardt, W.D. Phages and the evolution of bacterial pathogens: From genomic rearrangements to lysogenic conversion. Microbiol. Mol. Biol. Rev. 2004, 68, 560-602. [CrossRef] [PubMed]

5. Decker, K.B.; Hinton, D.M. Transcription regulation at the core: Similarities among bacterial, archaeal, and eukaryotic RNA polymerases. Annu. Rev. Microbiol. 2013, 67, 113-139. [CrossRef] [PubMed]

6. Murakami, K.S. X-ray crystal structure of Escherichia coli RNA polymerase sigma70 holoenzyme. J. Biol. Chem. 2013, 288, 9126-9134. [CrossRef] [PubMed]

7. Saecker, R.M.; Record, M.T., Jr.; Dehaseth, P.L. Mechanism of bacterial transcription initiation: RNA polymerase-Promoter binding, isomerization to initiation-competent open complexes, and initiation of RNA synthesis. J. Mol. Biol. 2011, 412, 754-771. [CrossRef] [PubMed]

8. Parshin, A.; Shiver, A.L.; Lee, J.; Ozerova, M.; Schneidman-Duhovny, D.; Gross, C.A.; Borukhov, S. DksA regulates RNA polymerase in Escherichia coli through a network of interactions in the secondary channel that includes Sequence Insertion 1. Proc. Natl. Acad. Sci. USA 2015, 112, E6862-E6871. [CrossRef] [PubMed]

9. Zenkin, N.; Yuzenkova, Y. New Insights into the Functions of Transcription Factors that Bind the RNA Polymerase Secondary Channel. Biomolecules 2015, 5, 1195-1209. [CrossRef] [PubMed]

10. Perederina, A.; Svetlov, V.; Vassylyeva, M.N.; Tahirov, T.H.; Yokoyama, S.; Artsimovitch, I.; Vassylyev, D.G. Regulation through the secondary channel-Structural framework for ppGpp-DksA synergism during transcription. Cell 2004, 118, 297-309. [CrossRef] [PubMed]

11. Mechold, U.; Potrykus, K.; Murphy, H.; Murakami, K.S.; Cashel, M. Differential regulation by ppGpp versus pppGpp in Escherichia coli. Nucleic Acids Res. 2013, 41, 6175-6189. [CrossRef] [PubMed]

12. Ross, W.; Sanchez-Vazquez, P.; Chen, A.Y.; Lee, J.H.; Burgos, H.L.; Gourse, R.L. ppGpp Binding to a Site at the RNAP-DksA Interface Accounts for Its Dramatic Effects on Transcription Initiation during the Stringent Response. Mol. Cell 2016, 62, 811-823. [CrossRef] [PubMed]

13. Paul, B.J.; Barker, M.M.; Ross, W.; Schneider, D.A.; Webb, C.; Foster, J.W.; Gourse, R.L. DksA: A critical component of the transcription initiation machinery that potentiates the regulation of rRNA promoters by ppGpp and the initiating NTP. Cell 2004, 118, 311-322. [CrossRef] [PubMed]

14. Rutherford, S.T.; Lemke, J.J.; Vrentas, C.E.; Gaal, T.; Ross, W.; Gourse, R.L. Effects of DksA, GreA, and GreB on transcription initiation: Insights into the mechanisms of factors that bind in the secondary channel of RNA polymerase. J. Mol. Biol. 2007, 366, 1243-1257. [CrossRef] [PubMed]

15. Roghanian, M.; Zenkin, N.; Yuzenkova, Y. Bacterial global regulators DksA/ppGpp increase fidelity of transcription. Nucleic Acids Res. 2015, 43, 1529-1536. [CrossRef] [PubMed]

16. Molodtsov, V.; Sineva, E.; Zhang, L.; Huang, X.; Cashel, M.; Ades, S.E.; Murakami, K. Allosteric effector ppGpp potentiates the inhibition of transcript initiation by DksA. Mol. Cell 2018, 69, 828-839.e5. [CrossRef] [PubMed]

17. Potrykus, K.; Wegrzyn, G.; Hernandez, V.J. Multiple mechanisms of transcription inhibition by ppGpp at the lambdap(R) promoter. J. Biol. Chem. 2002, 277, 43785-43791. [CrossRef] [PubMed] 
18. Magnusson, L.U.; Gummesson, B.; Joksimovic, P.; Farewell, A.; Nystrom, T. Identical, independent, and opposing roles of ppGpp and DksA in Escherichia coli. J. Bacteriol. 2007, 189, 5193-5202. [CrossRef] [PubMed]

19. Kanjee, U.; Ogata, K.; Houry, W.A. Direct binding targets of the stringent response alarmone (p)ppGpp. Mol. Microbiol. 2012, 85, 1029-1043. [CrossRef] [PubMed]

20. Henard, C.A.; Tapscott, T.; Crawford, M.A.; Husain, M.; Doulias, P.T.; Porwollik, S.; Liu, L.; McClelland, M.; Ischiropoulos, H.; Vazquez-Torres, A. The 4-cysteine zinc-finger motif of the RNA polymerase regulator DksA serves as a thiol switch for sensing oxidative and nitrosative stress. Mol. Microbiol. 2014, 91, 790-804. [CrossRef] [PubMed]

21. Vinella, D.; Potrykus, K.; Murphy, H.; Cashel, M. Effects on Growth by Changes of the Balance between GreA, GreB, and DksA Suggest Mutual Competition and Functional Redundancy in Escherichia coli. J. Bacteriol. 2012, 194, 261-273. [CrossRef] [PubMed]

22. Laptenko, O.; Lee, J.; Lomakin, I.; Borukhov, S. Transcript cleavage factors GreA and GreB act as transient catalytic components of RNA polymerase. EMBO J. 2003, 22, 6322-6334. [CrossRef] [PubMed]

23. Hinton, D.M. Transcriptional control in the prereplicative phase of T4 development. Virol. J. 2010, 7, 289. [CrossRef] [PubMed]

24. Geiduschek, E.P.; Kassavetis, G.A. Transcription of the T4 late genes. Virol. J. 2010, 7, 288. [CrossRef] [PubMed]

25. Mattson, T.; Vanhouwe, G.; Epstein, R.H. Isolation and Characterization of Conditional Lethal Mutations in the Mot Gene of Bacteriophage-T4. J. Mol. Biol. 1978, 126, 551-570. [CrossRef]

26. Studier, F.W.; Rosenberg, A.H.; Dunn, J.J.; Dubendorff, J.W. Use of T7 RNA polymerase to direct expression of cloned genes. Methods Enzymol. 1990, 185, 60-89. [PubMed]

27. Jeong, H.; Barbe, V.; Lee, C.H.; Vallenet, D.; Yu, D.S.; Choi, S.H.; Couloux, A.; Lee, S.W.; Yoon, S.H.; Cattolico, L.; et al. Genome sequences of Escherichia coli B strains REL606 and BL21(DE3). J. Mol. Biol. 2009, 394, 644-652. [CrossRef] [PubMed]

28. Kang, P.J.; Craig, E.A. Identification and characterization of a new Escherichia coli gene that is a dosagedependent suppressor of a dnaK deletion mutation. J. Bacteriol. 1990, 172, 2055-2064. [CrossRef] [PubMed]

29. Xiao, H.; Kalman, M.; Ikehara, K.; Zemel, S.; Glaser, G.; Cashel, M. Residual guanosine 3',5'-bispyrophosphate synthetic activity of relA null mutants can be eliminated by spoT null mutations. J. Biol. Chem. 1991, 266, 5980-5990. [PubMed]

30. Dressman, H.K.; Drake, J.W. Lysis and lysis inhibition in bacteriophage T4: RV mutations reside in the holin t gene. J. Bacteriol. 1999, 181, 4391-4396. [PubMed]

31. Schneider, C.A.; Rasband, W.S.; Eliceiri, K.W. NIH Image to ImageJ: 25 years of image analysis. Nat. Methods 2012, 9, 671-675. [CrossRef] [PubMed]

32. Lee, Y.; Yin, J. Imaging the propagation of viruses. Biotechnol. Bioeng. 1996, 52, 438-442. [CrossRef]

33. Racine, J.S. RStudio: A Platform-Independent IDE for R and Sweave. J. Appl. Econ. 2012, 27, 167-172. [CrossRef]

34. Wickham, H. ggplot2: Elegant Graphics for Data Analysis. In Use R; Springer: Berlin, Germany, 2009.

35. Carson, K. Single-Step Growth. In Molecular Biology of Bacteriophage T4; Karam, J.D., Kreuzer, K.N., Mosig, G., Hall, D.H., Eiserling, F.A., Black, L.W., Spicer, E.K., Kutter, E., Carlson, K., Miller, E.S., Eds.; American Society of Microbiology: Washington, DC, USA, 1994; pp. 434-437.

36. Hinton, D.M. Transcript analyses of the uvsX-40-41 region of bacteriophage T4. Changes in the RNA as infection proceeds. J. Biol. Chem. 1989, 264, 14432-14439. [PubMed]

37. Schroeder, A.; Mueller, O.; Stocker, S.; Salowsky, R.; Leiber, M.; Gassmann, M.; Lightfoot, S.; Menzel, W.; Granzow, M.; Ragg, T. The RIN: An RNA integrity number for assigning integrity values to RNA measurements. BMC Mol. Biol. 2006, 7, 3. [CrossRef] [PubMed]

38. Dobin, A.; Davis, C.A.; Schlesinger, F.; Drenkow, J.; Zaleski, C.; Jha, S.; Batut, P.; Chaisson, M.; Gingeras, T.R. STAR: Ultrafast universal RNA-seq aligner. Bioinformatics 2013, 29, 15-21. [CrossRef] [PubMed]

39. Liao, Y.; Smyth, G.K.; Shi, W. featureCounts: An efficient general purpose program for assigning sequence reads to genomic features. Bioinformatics 2014, 30, 923-930. [CrossRef] [PubMed]

40. James, T.D.; Cashel, M.; Hinton, D.M. A Mutation within the beta Subunit of Escherichia coli RNA Polymerase Impairs Transcription from Bacteriophage T4 Middle Promoters. J. Bacteriol. 2010, 192, 5580-5587. [CrossRef] [PubMed]

41. Hinton, D.M. Transcription from a bacteriophage T4 middle promoter using T4 motA protein and phage-modified RNA polymerase. J. Biol. Chem. 1991, 266, 18034-18044. [PubMed] 
42. Guild, N.; Gayle, M.; Sweeney, R.; Hollingsworth, T.; Modeer, T.; Gold, L. Transcriptional activation of bacteriophage T4 middle promoters by the motA protein. J. Mol. Biol. 1988, 199, 241-258. [CrossRef]

43. Schmittgen, T.D.; Livak, K.J. Analyzing real-time PCR data by the comparative C-T method. Nat. Protoc. 2008, 3, 1101-1108. [CrossRef] [PubMed]

44. Untergasser, A.; Cutcutache, I.; Koressaar, T.; Ye, J.; Faircloth, B.C.; Remm, M.; Rozen, S.G. Primer3-New capabilities and interfaces. Nucleic Acids Res. 2012, 40, e115. [CrossRef] [PubMed]

45. Koressaar, T.; Remm, M. Enhancements and modifications of primer design program Primer3. Bioinformatics 2007, 23, 1289-1291. [CrossRef] [PubMed]

46. Gerber, J.S.; Hinton, D.M. An N-terminal mutation in the bacteriophage T4 motA gene yields a protein that binds DNA but is defective for activation of transcription. J. Bacteriol. 1996, 178, 6133-6139. [CrossRef] [PubMed]

47. Hsieh, M.L.; James, T.D.; Knipling, L.; Waddell, M.B.; White, S.; Hinton, D.M. Architecture of the Bacteriophage T4 Activator MotA/Promoter DNA Interaction during Sigma Appropriation. J. Biol. Chem. 2013, 288, 27607-27618. [CrossRef] [PubMed]

48. Hinton, D.M.; March-Amegadzie, R.; Gerber, J.S.; Sharma, M. Bacteriophage T4 middle transcription system: T4-modified RNA polymerase; AsiA, a sigma 70 binding protein; and transcriptional activator MotA. Methods Enzymol. 1996, 274, 43-57. [PubMed]

49. Potrykus, K.; Vinella, D.; Murphy, H.; Szalewska-Palasz, A.; D'Ari, R.; Cashel, M. Antagonistic regulation of Escherichia coli ribosomal RNA rrnB P1 promoter activity by GreA and DksA. J. Biol. Chem. 2006, 281, 15238-15248. [CrossRef] [PubMed]

50. Gallet, R.; Kannoly, S.; Wang, I.N. Effects of bacteriophage traits on plaque formation. BMC Microbiol. 2011, 11, 181. [CrossRef] [PubMed]

51. Abedon, S.T.; Culler, R.R. Optimizing bacteriophage plaque fecundity. J. Theor. Biol. 2007, 249, 582-592. [CrossRef] [PubMed]

52. Benson, K.H.; Kreuzer, K.N. Role of MotA transcription factor in bacteriophage T4 DNA replication. J. Mol. Biol. 1992, 228, 88-100. [CrossRef]

53. Miller, E.S.; Kutter, E.; Mosig, G.; Arisaka, F.; Kunisawa, T.; Ruger, W. Bacteriophage T4 genome. Microbiol. Mol. Biol. Rev. 2003, 67, 86-156. [CrossRef] [PubMed]

54. Stitt, B.; Hinton, D.M. Regulation of Middle-Mode Transcription. In Molecular Biology of Bacteriophage T4; Karam, J.D., Ed.; American Society for Microbiology: Washington, DC, USA, 1994; pp. 142-160.

55. Truncaite, L.; Piesiniene, L.; Kolesinskiene, G.; Zajanckauskaite, A.; Driukas, A.; Klausa, V.; Nivinskas, R. Twelve new MotA-dependent middle promoters of bacteriophage T4: Consensus sequence revised. J. Mol. Biol. 2003, 327, 335-346. [CrossRef]

56. Sozhamannan, S.; Stitt, B.L. Effects on mRNA degradation by Escherichia coli transcription termination factor Rho and pBR322 copy number control protein Rop. J. Mol. Biol. 1997, 268, 689-703. [CrossRef] [PubMed]

57. Sozhamannan, S.; Morris, J.G.; Stitt, B.L. Instability of pUC19 in Escherichia coli transcription termination factor mutant, rho026. Plasmid 1999, 41, 63-69. [CrossRef] [PubMed]

58. Luke, K.; Radek, A.; Liu, X.; Campbell, J.; Uzan, M.; Haselkorn, R.; Kogan, Y. Microarray analysis of gene expression during bacteriophage T4 infection. Virology 2002, 299, 182-191. [CrossRef] [PubMed]

59. Sanson, B.; Uzan, M. Post-transcriptional controls in bacteriophage T4: Roles of the sequence-specific endoribonuclease RegB. FEMS Microbiol. Rev. 1995, 17, 141-150. [CrossRef] [PubMed]

60. Uzan, M. Bacteriophage T4 RegB endoribonuclease. Methods Enzymol. 2001, 342, 467-480. [PubMed]

61. Barker, M.M.; Gaal, T.; Josaitis, C.A.; Gourse, R.L. Mechanism of regulation of transcription initiation by ppGpp. I. Effects of ppGpp on transcription initiation in vivo and in vitro. J. Mol. Biol. 2001, 305, 673-688. [CrossRef] [PubMed]

62. Travers, A.A. Promoter sequence for stringent control of bacterial ribonucleic acid synthesis. J. Bacteriol. 1980, 141, 973-976. [PubMed]

63. Haugen, S.P.; Ross, W.; Gourse, R.L. Advances in bacterial promoter recognition and its control by factors that do not bind DNA. Nat. Rev. Microbiol. 2008, 6, 507-519. [CrossRef] [PubMed]

64. Zhang, Y.; Mooney, R.A.; Grass, J.A.; Sivaramakrishnan, P.; Herman, C.; Landick, R.; Wang, J.D. DksA guards elongating RNA polymerase against ribosome-stalling-induced arrest. Mol. Cell 2014, 53, 766-778. [CrossRef] [PubMed] 
65. Kolmsee, T.; Delic, D.; Agyenim, T.; Calles, C.; Wagner, R. Differential stringent control of Escherichia coli rRNA promoters: Effects of ppGpp, DksA and the initiating nucleotides. Microbiology 2011, 157, 2871-2879. [CrossRef] [PubMed]

66. Henard, C.A.; Bourret, T.J.; Song, M.; Vazquez-Torres, A. Control of redox balance by the stringent response regulatory protein promotes antioxidant defenses of Salmonella. J. Biol. Chem. 2010, 285, 36785-36793. [CrossRef] [PubMed]

67. Henard, C.A.; Vazquez-Torres, A. DksA-dependent resistance of Salmonella enterica serovar Typhimurium against the antimicrobial activity of inducible nitric oxide synthase. Infect. Immun. 2012, 80, 1373-1380. [CrossRef] [PubMed]

68. Sharma, A.K.; Payne, S.M. Induction of expression of hfq by DksA is essential for Shigella flexneri virulence. Mol. Microbiol. 2006, 62, 469-479. [CrossRef] [PubMed]

69. Chen, A.I.; Goulian, M. A network of regulators promotes dehydration tolerance in Escherichia coli. Environ. Microbiol. 2018, 20, 1283-1295. [CrossRef] [PubMed]

70. Crawford, M.A.; Henard, C.A.; Tapscott, T.; Porwollik, S.; McClelland, M.; Vazquez-Torres, A. DksA-Dependent Transcriptional Regulation in Salmonella Experiencing Nitrosative Stress. Front. Microbiol. 2016, 7, 444. [CrossRef] [PubMed]

71. Holley, C.L.; Zhang, X.J.; Fortney, K.R.; Ellinger, S.; Johnson, P.; Baker, B.; Liu, Y.L.; Janowicz, D.M.; Katz, B.P.; Munson, R.S.; et al. DksA and (p)ppGpp Have Unique and Overlapping Contributions to Haemophilus ducreyi Pathogenesis in Humans. Infect. Immun. 2015, 83, 3281-3292. [CrossRef] [PubMed]

72. Wilkens, K.R.W. Transcription from early promoters. In Molecular Biology of Bacteriophage T4; Karam, J.D., Kreuzer, K.N., Mosig, G., Hall, D.H., Eiserling, F.A., Black, L.W., Spicer, E.K., Kutter, E., Carlson, K., Miller, E.S., Eds.; American Society for Microbiology: Washington, DC, USA, 1994; pp. 132-141.

73. Webb, C.; Moreno, M.; Wilmes-Riesenberg, M.; Curtiss, R., 3rd; Foster, J.W. Effects of DksA and ClpP protease on sigma S production and virulence in Salmonella typhimurium. Mol. Microbiol. 1999, 34, 112-123. [CrossRef] [PubMed]

74. Potrykus, K.; Murphy, H.; Philippe, N.; Cashel, M. ppGpp is the major source of growth rate control in E. coli. Environ. Microbiol. 2011, 13, 563-575. [CrossRef] [PubMed]

75. Li, G.; Young, K.D. A cAMP-independent carbohydrate-driven mechanism inhibits tnaA expression and TnaA enzyme activity in Escherichia coli. Microbiology 2014, 160, 2079-2088. [CrossRef] [PubMed]

76. Traxler, M.F.; Summers, S.M.; Nguyen, H.T.; Zacharia, V.M.; Hightower, G.A.; Smith, J.T.; Conway, T. The global, ppGpp-mediated stringent response to amino acid starvation in Escherichia coli. Mol. Microbiol. 2008, 68, 1128-1148. [CrossRef] [PubMed]

77. Shokri, A.; Veide, A.; Larsson, G. RelA1 gene control of Escherichia coli lipid structure and cell performance during glucose limited fed-batch conditions. Appl. Microbiol. Biotechnol. 2006, 73, 464-473. [CrossRef] [PubMed]

78. Santangelo, T.J.; Artsimovitch, I. Termination and antitermination: RNA polymerase runs a stop sign. Nat. Rev. Microbiol. 2011, 9, 319-329. [CrossRef] [PubMed]

79. Grainger, D.C. Structure and function of bacterial H-NS protein. Biochem. Soc. Trans. 2016, 44, 1561-1569. [CrossRef] [PubMed]

80. Ali, S.S.; Beckett, E.; Bae, S.J.; Navarre, W.W. The 5.5 Protein of Phage T7 Inhibits H-NS through Interactions with the Central Oligomerization Domain. J. Bacteriol. 2011, 193, 4881-4892. [CrossRef] [PubMed]

81. Ho, C.H.; Wang, H.C.; Ko, T.P.; Chang, Y.C.; Wang, A.H.J. The T4 Phage DNA Mimic Protein Arn Inhibits the DNA Binding Activity of the Bacterial Histone-like Protein H-NS. J. Biol. Chem. 2014, 289, 27046-27054. [CrossRef] [PubMed]

82. Wagemans, J.; Delattre, A.S.; Uytterhoeven, B.; de Smet, J.; Cenens, W.; Aertsen, A.; Ceyssens, P.J.; Lavigne, R. Antibacterial phage ORFans of Pseudomonas aeruginosa phage LUZ24 reveal a novel MvaT inhibiting protein. Front. Microbiol. 2015, 6, 1242. [CrossRef] [PubMed]

(C) 2018 by the authors. Licensee MDPI, Basel, Switzerland. This article is an open access article distributed under the terms and conditions of the Creative Commons Attribution (CC BY) license (http:/ / creativecommons.org/licenses/by/4.0/). 